\title{
Middle atmosphere water vapour and dynamical features in aircraft measurements and ECMWF analyses
}

\author{
D. G. Feist ${ }^{1, *}$, A. J. Geer ${ }^{2, * *}$, S. Müller ${ }^{1}$, and N. Kämpfer ${ }^{1}$ \\ ${ }^{1}$ Institute of Applied Physics, University of Bern, Switzerland \\ ${ }^{2}$ Data Assimilation Research Centre, University of Reading, UK \\ * now at: Max Planck Institute for Biogeochemistry, Jena, Germany \\ ** now at: European Centre for Medium-Range Weather Forecasts (ECMWF), Reading, UK
}

Received: 20 November 2006 - Published in Atmos. Chem. Phys. Discuss.: 10 January 2007

Revised: 4 July 2007 - Accepted: 8 October 2007 - Published: 15 October 2007

\begin{abstract}
The European Centre for Medium-Range Weather Forecasts (ECMWF) provides global analyses of atmospheric humidity from the ground to the lower mesosphere. Unlike in the troposphere, in the stratosphere no humidity observations are assimilated. Humidity analyses here are essentially the results of a free-running model constrained by the ECMWF's analysed wind fields. So far only the broad-scale features of the resulting stratospheric water vapour distribution have been validated. This study provides the first indepth comparison of stratospheric humidity from ECMWF with observations from an airborne microwave radiometer that has measured the distribution of stratospheric water vapour over an altitude range of roughly $15-60 \mathrm{~km}$ on several flight campaigns since 1998. The aircraft measurements provide a horizontal resolution that cannot be achieved by current satellite instruments. This study examines dynamical features in the moisture fields such as filamentation and the vortex edge, finding that features in the ERA-40 humidity analyses often do correspond to real atmospheric events that are seen in the aircraft measurements. However, the comparisons also show that in general the ECMWF model produces an unrealistically moist mesosphere. As a result it cannot replicate the descent of relatively dry mesospheric air into the polar vortex in winter and spring.
\end{abstract}

\section{Introduction}

Stratospheric water vapour and its variability over time has been an issue of continuous scientific interest ever since Brewer (1949) explained the dryness of the stratosphere. He

Correspondence to: D. G. Feist

(dfeist@bgc-jena.mpg.de) proposed that air is dehydrated as it enters the stratosphere through the very low temperatures at the tropical tropopause. Stratospheric $\mathrm{H}_{2} \mathrm{O}$ entry values in the tropics can now be simulated with good accuracy from synoptic-scale velocity and temperature fields (Fueglistaler et al., 2005). Seasonal variability in tropopause temperature causes a seasonal cycle in the mixing ratio of air entering the stratosphere; these variations are transported upwards and polewards in the stratospheric Brewer-Dobson circulation (e.g. Plumb, 2002). The gradual upward progress of these anomalies, over a period of several years, is known as the tape-recorder effect (Mote et al., 1995). Interannual variability in the amount of water vapour entering the stratosphere can be explained with tropical tropopause temperature anomalies (Randel et al., 2004b).

In the wintertime polar vortex, in the lower stratosphere, low temperatures can cause rapid dehydration associated with the formation of Polar Stratospheric Clouds (PSCs). This effect is much stronger in the Antarctic than in the Arctic. Outside these areas, water vapour is a long-lived tracer in the stratosphere; water vapour amounts are increased through methane oxidation, with a timescale of years in the lower stratosphere and $\sim 100$ days near the stratopause (Le Texier et al., 1988). In the mesosphere, water vapour is lost through photolysis. During winter, dry air from the mesosphere descends into the stratosphere through the polar vortex, as modelled by Le Texier et al. (1988) and observed by e.g. Lahoz et al. (1994); Aellig et al. (1996); Plumb et al. (2002); Engel et al. (2006).

Observations of stratospheric $\mathrm{H}_{2} \mathrm{O}$ are limited in time and space and there are biases ranging from $10 \%$ up to $40 \%$ between different instruments and measurement methods (Kley et al., 2000). This study investigates stratospheric $\mathrm{H}_{2} \mathrm{O}$ profiles derived from measurements of the airborne microwave

Published by Copernicus Publications on behalf of the European Geosciences Union. 
radiometer AMSOS (Airborne Microwave Stratospheric Observing System). Given the very localised nature of the AMSOS observations, it is particularly difficult to find colocations with independent data sources. Instead we compare AMSOS to the $\mathrm{H}_{2} \mathrm{O}$ and dynamical fields from the ECMWF (European Centre for Medium Range Weather Forecasts) analyses. We compare to ERA-40 reanalyses (Uppala et al., 2005 ) in the years up to 2001, and to the operational analyses for 2002.

The AMSOS instrument has covered large parts of the Northern Hemisphere onboard a Learjet 35 A of the Swiss Air Force during yearly campaigns since 1998. It follows in the footsteps of earlier measurements with an older instrument on the same aircraft by Peter (1998). The data set for this analysis covered five missions from 1998 to 2002. AMSOS measures the $\mathrm{H}_{2} \mathrm{O}$ distribution from the flight altitude up to about $60 \mathrm{~km}$, thus providing a 2-D cut through the atmosphere with very good horizontal resolution. Such a unique view of the atmosphere cannot easily be produced by other methods, especially not by most satellite instruments.

In the ECMWF system, no water vapour observations are assimilated in the stratosphere. Hence the water vapour field is largely determined by input from the troposphere, modelled stratospheric transport and methane oxidation in the stratosphere, and water vapour photolysis in the mesosphere (Dethof, 2003). Simmons et al. (1999) examined a development version of the ERA-40 system, finding a broadly realistic distribution of water vapour in the stratosphere. Oikonomou and O'Neill (2006) compared analysed ERA-40 humidities to observations from the Upper Atmosphere Research Satellite (UARS) and to aircraft measurements. ERA-40 specific humidities were found to be too low by $10-20 \%$ in the mid- and upper-stratosphere $(50 \mathrm{hPa}$ upwards). Another problem in the ERA-40 humidities is the representation of the tape recorder signal; Oikonomou and O'Neill (2006) showed that ERA-40 transports the signal far too rapidly in the stratosphere, with mean ascent rates over the tropics of $0.5 \times 10^{-3} \mathrm{~m} / \mathrm{s}$ compared to observed values of $0.2-0.4 \times 10^{-3} \mathrm{~m} / \mathrm{s}$. Equivalently, the Brewer-Dobson circulation is too fast. ECMWF stratospheric humidities have otherwise seen little validation though operational moisture analyses were useful in illustrating the dynamical evolution of the remarkable $2002 \mathrm{SH}$ vortex split and showed many similarities with the potential vorticity (PV) fields (Simmons et al., 2005).

Here we investigate stratospheric humidities in the ECMWF system by comparison to the very high horizontal resolution measurements of AMSOS. In reverse, we can use ECMWF dynamical and moisture fields to investigate the geophysical reality of the AMSOS data at horizontal resolutions in the range of $50-100 \mathrm{~km}$ which are not available from any other observation type. Of particular interest are the sharp gradients in the water vapour field at the boundaries between the vortex and the surf-zone, between the surf-zone and the tropical pipe (see Plumb, 2002, for the terminology), and where very different air masses are brought into close proximity through filamentation.

\section{AMSOS observations}

Many atmospheric molecules like water vapour, oxygen, ozone and other trace gases have rotational spectral lines in the microwave range of the electromagnetic spectrum. Due to their temperature, these molecules emit electromagnetic radiation with characteristic spectral line shapes that can be detected by passive radiometers. The intensity of the emitted radiation depends on the atmospheric temperature at a given altitude (which has to be known for this purpose) and the number density of the molecules (which can be determined). Since the shape of the emitted spectral line depends mainly on pressure, the resulting spectrum also contains information about the altitude distribution of the molecules.

The microwave radiometer AMSOS observes spectral emissions of atmospheric water vapour near $183.3 \mathrm{GHz}$ from an aircraft. The instrument is an uncooled heterodyne receiver with a bandwidth of roughly $1 \mathrm{GHz}$. The two acousto-optical spectrometers resolve the water vapour line to roughly $1 \mathrm{MHz}$ over the whole bandwidth and roughly $25 \mathrm{kHz}$ near the line center. Details of the instrument are given by Vasić et al. (2005). A single spectrum is measured every $10-15 \mathrm{~s}$ during the flight. Since individual spectra are too noisy, about 20 of them are integrated for the profile retrieval. From these integrated spectra, altitude profiles of water vapour volume mixing ratio over an altitude range of roughly $15-60 \mathrm{~km}$ can be retrieved along the flight track.

The horizontal resolution depends on the distance and the course that the aircraft travels during the integration time. It takes about five minutes to measure 20 spectra and the aircraft typically travels with a ground speed of $700-800 \mathrm{~km} / \mathrm{h}$. Therefore the resulting horizontal resolution is in the order of $50-60 \mathrm{~km}$.

The vertical resolution of such retrieved profiles is typically low because the vertical profiles are smoothed with the retrieval's averaging kernel (Rodgers, 2000). Figure 1 shows a typical AMSOS averaging kernel as an example. The averaging kernel provides vertical weighting functions that determine the vertical resolution of the retrieval. In the case of AMSOS, the width of these weighting functions is roughly $10-15 \mathrm{~km}$ in the stratosphere. This low vertical resolution is due to the fact that pressure-broadening of the spectral lines provides the only altitude information to the retrieval. Since many vertical weighting functions overlap in this region, the resulting altitude profile at each vertical level is a weighted average of the true profile with the averaging kernel.

Since 1998, the AMSOS instrument has taken part in yearly campaigns with a Learjet of the Swiss Air Force. A typical campaign took about one week and covered large parts of the Northern Hemisphere. Most AMSOS missions were coordinated with other European aircraft or balloon 


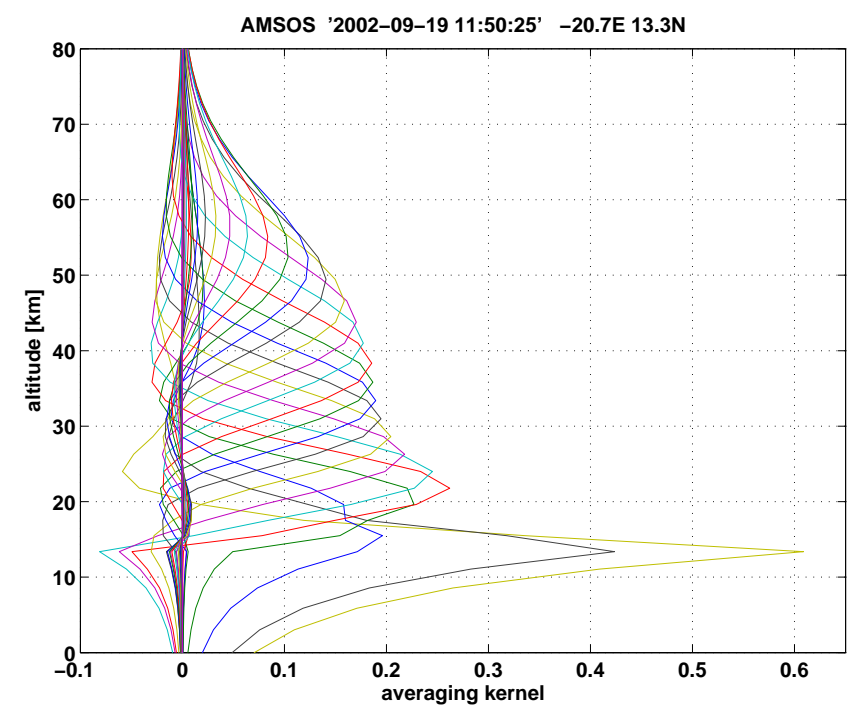

Fig. 1. A typical averaging kernel for the AMSOS version 2 retrieval. The averaging kernel determines the vertical resolution of the AMSOS data. Below $20 \mathrm{~km}$ the retrieval has a single weighting function that detects the total water vapour column between the aircraft flight altitude (typically around $12 \mathrm{~km}$ ) and the hygropause. Above $20 \mathrm{~km}$ altitude are the regular vertical weighting functions that retrieve stratospheric water vapour with a vertical resolution of roughly $10 \mathrm{~km}$.

campaigns. Table 1 shows the time frame, latitude range and partner campaigns (if any) of the individual AMSOS missions that were used for this study. In 2003, the AMSOS instrument was refurbished. Data from these later campaigns will be analyzed in a separate study.

In our preparatory work for this study, we compared AMSOS version 1 retrievals to ECMWF analyses and UARS climatology. Those comparisons revealed a number of artifacts in the retrievals. The most obvious was that the AMSOS humidities were typically $20 \%$ drier than ECMWF and the UARS climatology. The retrievals also contained sections in which the data appeared unphysical. For example, for a few consecutive profiles, the usual vertical gradient in stratospheric moisture was reversed, before returning to normal. These artifacts also disagreed with the ECMWF water vapour analyses. Such artifacts were perhaps to be expected given the difficulty of finding colocated observational data to validate such an instrument. We were able to identify a number of instrumental factors, such as drift effects and sudden changes in the operating conditions, which led to the observed spectra being unusable, and explained the artifacts.

In spring 2006 the whole AMSOS dataset was reprocessed, weeding out the unusable spectra and at the same time integrating more spectra that were measured under very similar conditions. The retrieval algorithm was also improved. The reprocessed data is known as version 2; we use
Table 1. AMSOS mission overview.

\begin{tabular}{crcr}
\hline Mission & Time period & Lat. range & Campaign \\
\hline 1 & 24 Aug 1998-28 Aug 1998 & $8-90^{\circ} \mathrm{N}$ & WAVE \\
2 & 5 Feb 1999-12 Feb 1999 & $17-81^{\circ} \mathrm{N}$ & THESEO 1999 \\
3 & 8 March 2000-14 March 2000 & $29-90^{\circ} \mathrm{N}$ & THESEO 2000/SOLVE \\
4 & 9 Nov 2001-13 Nov 2001 & $9-87^{\circ} \mathrm{N}$ & SPURT 2001 \\
5 & 16 Sep 2002-20 Sep 2002 & $5-90^{\circ} \mathrm{N}$ & Envisat validation \\
\hline
\end{tabular}

it throughout this study. The data quality in version 2 has improved significantly. Compared to the AMSOS version 1 profiles which have been used in earlier studies (Morland et al., 2006; Vasić et al., 2005), the new version 2 provides roughly four times as many retrieved profiles over the same flight distance due to the more efficient integration scheme. It also suffers less from instrumental artifacts in the lower retrieval layers. However, the individual profiles have become slightly noisier as a result of the reduced integration time and less regularization in the retrieval.

AMSOS version 2 uses the software packages ARTS (Buehler et al., 2005) and QPack (Eriksson et al., 2005) to retrieve water vapour profiles from the measured spectra with the Optimal Estimation Method (Rodgers, 2000). The a priori profile and the covariance matrix that is required by this retrieval method was derived from the humidity climatology data of the ERA-40 data set. The same a priori information was used for all profiles to avoid time or latitude-dependent influences on the retrieved profiles. External retrieval parameters like temperature and pressure profiles along the flight track were taken from ECMWF analysis data on model levels. Above the ECMWF model top $(0.1 \mathrm{hPa})$, the CIRA-86 climatology (Fleming et al., 1990) was used instead.

The measurement response function in Fig. 2 shows the influence of the a priori profile at different altitude levels. The measurement response provides a rough estimate on how strongly the retrieved profile depends on the a priori profile at a given altitude. A value of zero means that the data is completely determined by the a priori profile while a value near $100 \%$ suggests that the data is almost independent of the a priori profile. The plots in this study only show AMSOS data with a measurement response value of at least $50 \%$, which is typically in an altitude range of $12-60 \mathrm{~km}$. In the range from $15-55 \mathrm{~km}$, the measurement response is usually above $80-90 \%$, which means that the retrieved profile is mostly independent of the a priori profile.

\section{ECMWF analyses}

We examine analyses from two different versions of the ECMWF system, which is extensively documented at http: //www.ecmwf.int/research/ifsdocs/. For comparisons from 1998 to 2001, ERA-40 re-analyses (Uppala et al., 2005) are used. For comparisons in 2002, operational analyses are 


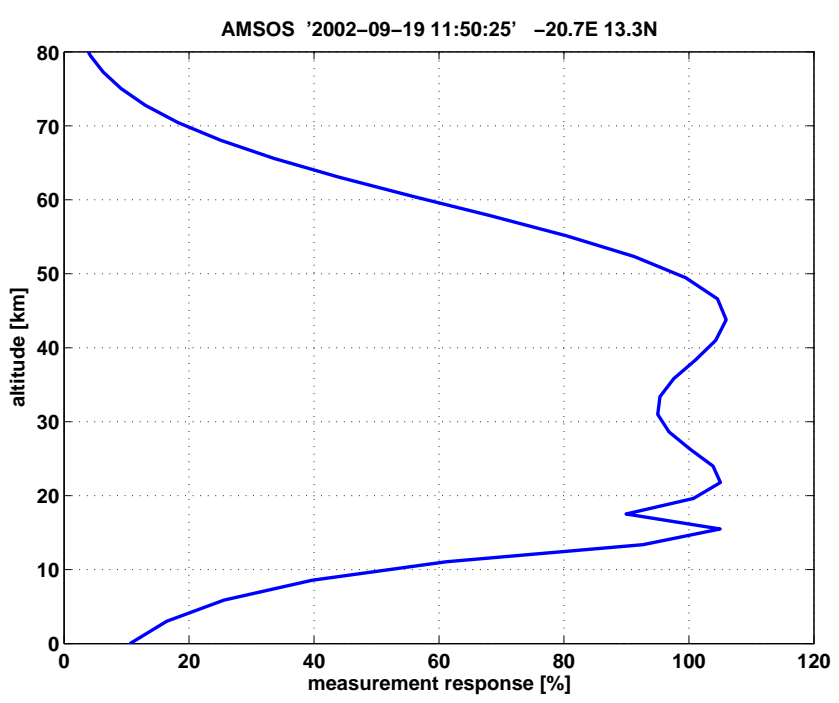

Fig. 2. Measurement response of the AMSOS version 2 retrieval for the whole altitude range. The measurement response provides a rough estimate on how strongly the retrieved profile depends on the a priori profile at a given altitude. A value of zero means that the data is completely determined by the a priori profile while a value near $100 \%$ suggests that the data is almost independent of the a priori profile.

used. In ERA-40, observations are assimilated using threedimensional variational (3D-Var) data assimilation, and in the operational analyses, four-dimensional variational (4DVar) data assimilation. In both cases, the assimilating model has 60 levels in the vertical, extending to $0.1 \mathrm{hPa}$. The horizontal resolution is T159 in ERA-40 and T511 in the operational analyses. Apart from one difference noted below, stratospheric water vapour is treated in the same way in both ECMWF variants.

\subsection{Dynamical fields}

In the stratosphere in the ECMWF analyses, temperature information comes primarily from satellite observations. The ERA-40 stratospheric analyses show a reasonable description of dynamical features such as major warmings, but there are a few known problems, especially in the pre-1979 era (Uppala et al., 2005). Problems that affect the time period studied are an unrealistic oscillatory temperature structure in the vertical in polar regions (Randel et al., 2004a; Uppala et al., 2005), and the excessively fast Brewer-Dobson circulation (Oikonomou and O'Neill, 2006).

In this paper we have obtained ECMWF temperature, pressure, geopotential height and wind fields. From the wind and temperature fields we have derived Ertel's potential vorticity, which is not archived at levels above $850 \mathrm{~K}$. From the ECMWF potential vorticity we derived equivalent latitude using the technique outlined in the introduction of Allen and
Nakamura (2003), though note we did not use the PV-like tracer method described in the bulk of that paper.

\subsection{Stratospheric water vapour}

In the ECMWF analyses, water vapour observations are not assimilated in the stratosphere. Instead, water vapour increments are forced to be zero above a diagnosed model tropopause. In the analysis versions examined here, the model removes any supersaturation of water vapour, which is important in the cold temperatures of the lower stratosphere in the wintertime polar vortices, and at the tropical tropopause. However, we should note that since September 2006 the operational ECMWF analyses have changed to allow supersaturation with respect to ice.

Methane oxidation and the photolysis of $\mathrm{H}_{2} \mathrm{O}$ are parametrised by changing specific humidity, $q$, at a rate, $R$, set by:

$R=k_{1}(Q-q)-k_{2} q$.

The first term describes methane oxidation as a relaxation towards a fixed specific humidity $Q$, based on the observation that the sum of mixing ratios $2\left[\mathrm{CH}_{4}\right]+\left[\mathrm{H}_{2} \mathrm{O}\right]$ is observed to be approximately conserved over much of the stratosphere (e.g. Randel et al., 1998), and by assuming the rate of conversion from methane to water vapour is proportional to the amount of methane. The rate coefficient $k_{1}$ is zero at $100 \mathrm{hPa}$ and below, and increases towards the mesosphere, where at $0.5 \mathrm{hPa}$ it corresponds to a time constant of 100 days. The second term accounts for photolysis of $\mathrm{H}_{2} \mathrm{O}$ in the mesosphere, where q decreases at a rate set by $k_{2}$, which is zero at all levels below $0.2 \mathrm{hPa}$. It is important to note that the value of $Q$ was set to 6 ppmv in ERA-40, and to 6.8 ppmv in the operational analyses. This was intended to increase, and hence improve, upper stratospheric humidities. It was introduced as a result of comparing the first few years of ERA-40 analyses (done in a production stream that started in 1989) with the UARS climatology of Randel et al. (1998). This new value has been used in the operational analyses since April 2002 (A. Simmons, personal communication, and Uppala et al., 2005, pages 2998-2999).

\subsection{Long-term stability of ECMWF humidities}

Before comparing ECMWF humidities against AMSOS retrievals from 1998 to 2002, it is interesting to examine the long-term stability of the analyses, and especially to look for any discontinuity between ERA-40 and the operational analyses. Interannual variability in data assimilation systems can arise simply from changes in the number, type, or calibration of observations used (e.g. Bengtsson et al., 2004), as well as from more obvious mechanisms such as changes in the model or data assimilation system, such as there is between ERA-40 and the operational analyses.

Figure 3 shows humidity anomalies in the tropical stratosphere from the ECMWF analyses. Humidity anomalies 


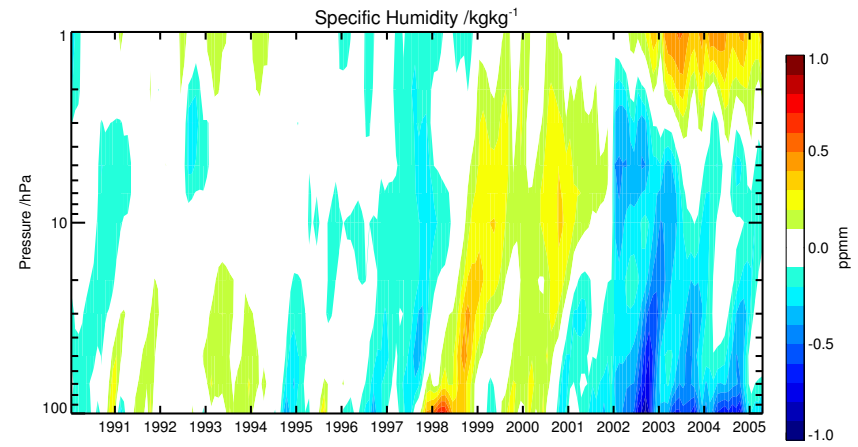

Fig. 3. Time series of deseasonalised humidity anomalies from the ECMWF analyses, averaged over the region $20^{\circ} \mathrm{S}$ to $20^{\circ} \mathrm{N}$. ERA-40 analyses are presented up until December 2001; operational analyses thereafter.

have been calculated with respect to the mean seasonal cycle of the ERA-40 analyses for the period 1990 to 2002. There are clear interannual variations, with the analyses moister than usual between 1998 and 2000 at $100 \mathrm{hPa}$. The anomalies appear to propagate upward, as would be expected in the ascending branch of the Brewer-Dobson circulation. Figure 3 can be compared to Fig. 2 of Randel et al. (2004b), which shows water vapour anomalies calculated from HALOE data. Both datasets show interannual variability of a similar magnitude. However, the anomalies propagate to the upper stratosphere with about two years' time lag in the HALOE observations, but only a year in the ECMWF analyses, illustrating the excessively fast Brewer-Dobson circulation in ERA-40. Between 1992 and 1998 there are large discrepancies between the interannual variability seen in the HALOE and ERA-40 datasets, but after this, there is broad agreement: higher than normal humidities in the lower stratosphere from 1998 to 2001, and lower than normal afterwards.

From January 2002 onwards, Fig. 3 shows operational ECMWF humidity anomalies, but they are still calculated as departures from the 1990 to 2002 mean ERA-40 seasonal cycle. The operational analyses are dryer in the mid and lower stratosphere, particularly in the moist phase of the tape recorder (at $100 \mathrm{hPa}$, roughly July to October). In the upper stratosphere, the analyses are moister, due to the change in the methane oxidation parameterisation described in Sect. 3.2. The relaxation value in Eq. (1) was increased from 6 to $6.8 \mathrm{ppmv}$ in April 2002 and there is a clear spinup in upper-stratospheric humidities over the following year, consistent with the $\sim 100$ day chemical timescale in the parametrisation at these levels.

Figure 4 is similar to Fig. 3 but for the north pole. It appears that the moist anomalies seen at the equatorial tropopause between 1998 and 2000 have propagated as far as the north pole with a timescale of about a year. Such propagation can be seen more clearly in time-latitude plots (not

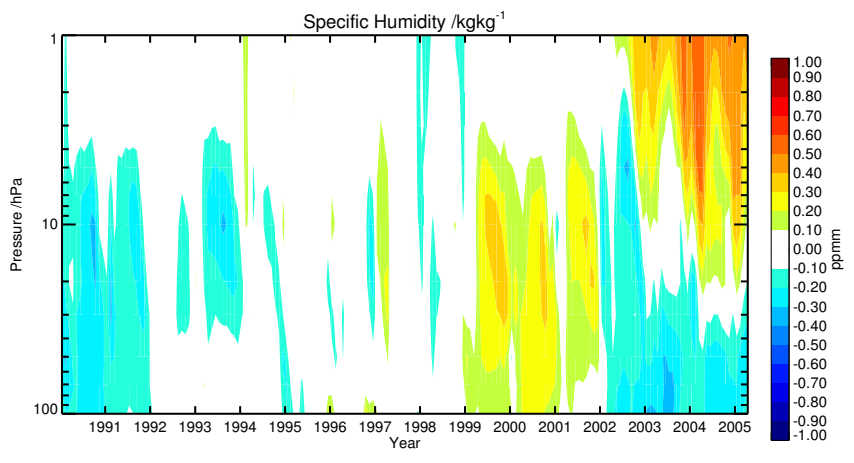

Fig. 4. Time series of deseasonalised humidity anomalies from the ECMWF analyses, averaged over the region $70^{\circ} \mathrm{N}$ to $90^{\circ} \mathrm{N}$. ERA-40 analyses are presented up until December 2001; operational analyses thereafter.

shown here) and can also be seen in the observations in Fig. 4 of Randel et al. (2004b). However, not all anomalies seen in the ERA-40 data in Fig. 3 propagate to the north pole.

The operational analyses in Fig. 4 after January 2002 are dryer in the lower stratosphere and moister in the upper stratosphere, similar to the behaviour in the tropics. In the following comparisons, we should clearly expect to treat the ERA-40 analyses and the post-2002 operational analyses as two separate datasets with somewhat different properties.

\section{UARS climatology}

The object of this comparison is to understand the strengths and weaknesses of both ECMWF and AMSOS humidities. Hence neither can or should be treated as the "truth" to which the other is being compared. To help understand differences between the datasets, we take the climatology of Randel et al. (1998) as an independent estimate of the stratospheric water vapour distribution.

Randel and coworkers binned water vapour retrievals from HALOE on UARS by equivalent latitude and pressure level and constructed a seasonal climatology from this using harmonic regression analysis. Water vapour observations from the Microwave Limb Sounder (MLS), also on UARS, were used to fill gaps in HALOE coverage at polar latitudes in winter. We use the version of this climatology available from the SPARC data centre at http://www.sparc.sunysb.edu/html/ uars_index.html, based on the years 1991 to 1999 , hence incorporating 2 more years' data than was available when Randel et al. (1998) was written.

The UARS climatology was mapped to AMSOS observation locations using the ECMWF analyses. In the vertical, this was done using ECMWF temperatures and pressures, and in the horizontal, using PV equivalent latitude derived from the analyses (see Sect. 3.1). Climatological monthly means were treated as representing the 15th day 

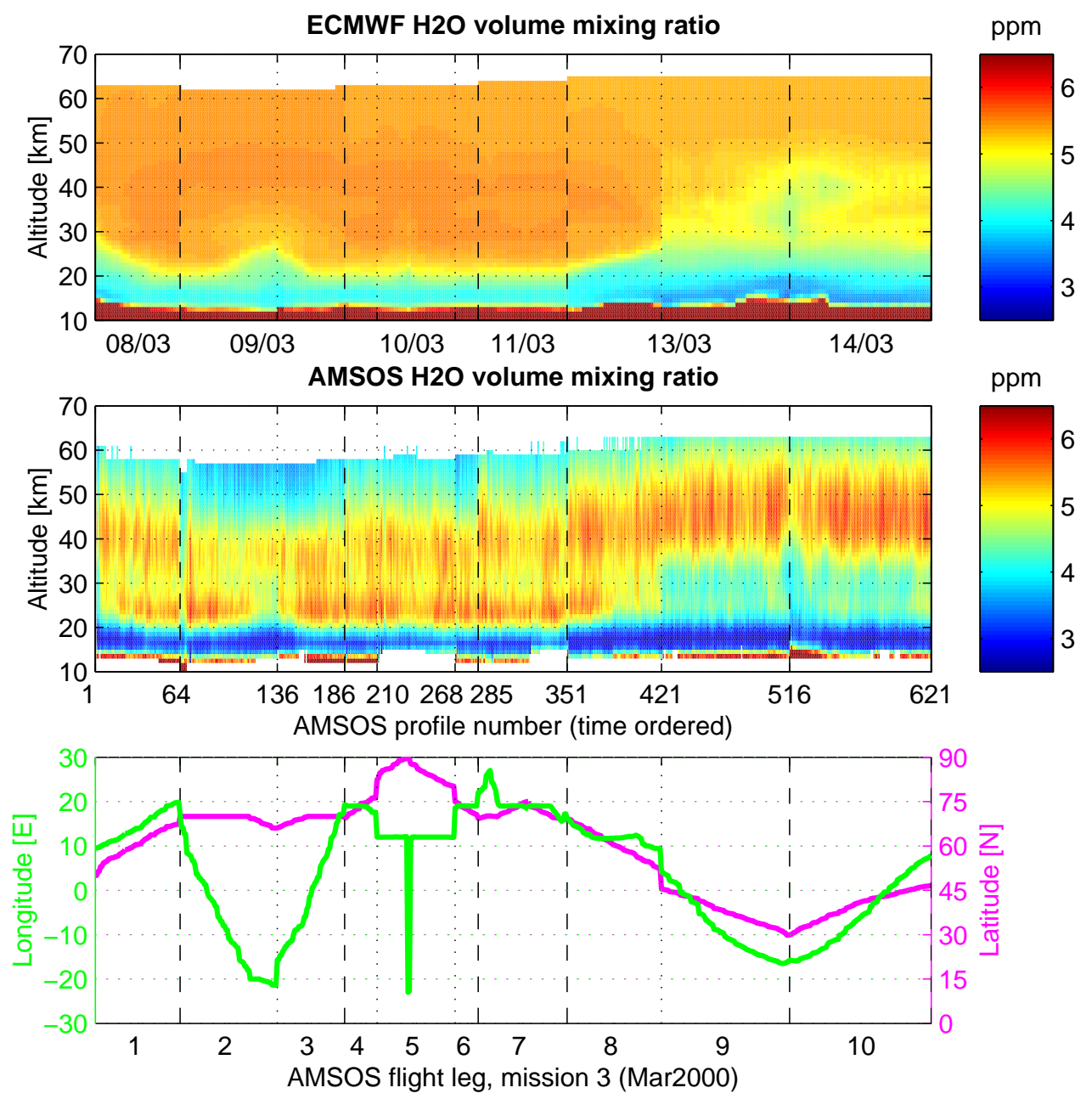

Fig. 5. Overview of the complete AMSOS Mission 3 (8-14 March 2000). The top plot shows ECMWF ERA-40 humidity profiles that correspond to the measured AMSOS profiles in the centre plot. The bottom plot shows the position of the measurements. The AMSOS profiles are ordered by time and numbered. Measurements from different days are separated by vertical dashed lines, while dotted lines separate different flight legs.

of the month, and were interpolated in time to the AMSOS dates.

\section{Detailed comparisons of AMSOS and ECMWF data}

Figure 5 shows all AMSOS retrievals from mission 3 (March 2000) ordered by measurement time. It also shows ECMWF analysed humidities interpolated to the same positions. The aircraft flew from Switzerland to the North Pole, then south towards the equator, and finally back to Switzerland. Hence the centre-left of the figure (profiles 1 to 420 ) represents the high latitudes and the polar vortex, and the right of the figure (profiles 421 top 621) shows the midlatitudes and subtropics.

As an example of a late summer mission, Fig. 6 shows ECMWF and AMSOS moisture along the AMSOS flight tracks for mission 5 (September 2002). Profiles 0-216 were taken in the region of the north pole; $318-482$ in the subtropics; the rest of the profiles are representative of the midlatitudes. As before, the largest scale features are similar in both, except for the lack of dry air in the ECMWF mesosphere. Note that, since this is summer, there is no sign of descent of dry air in the upper stratosphere at high latitudes in the AMSOS observations. In this figure we compare to ECMWF operational analyses, unlike the other missions, which we can compare to ERA-40. The differences between the two analysis types will be further be discussed in Sect. 5.4.

Both ECMWF and AMSOS show the expected zonal distribution of stratospheric water vapour, which results from the upwards and polewards transport of dry air from the tropical tropopause, with that air, over time, being moistened through methane oxidation. Hence both AMSOS and ECMWF show an increase in humidity from the tropopause 

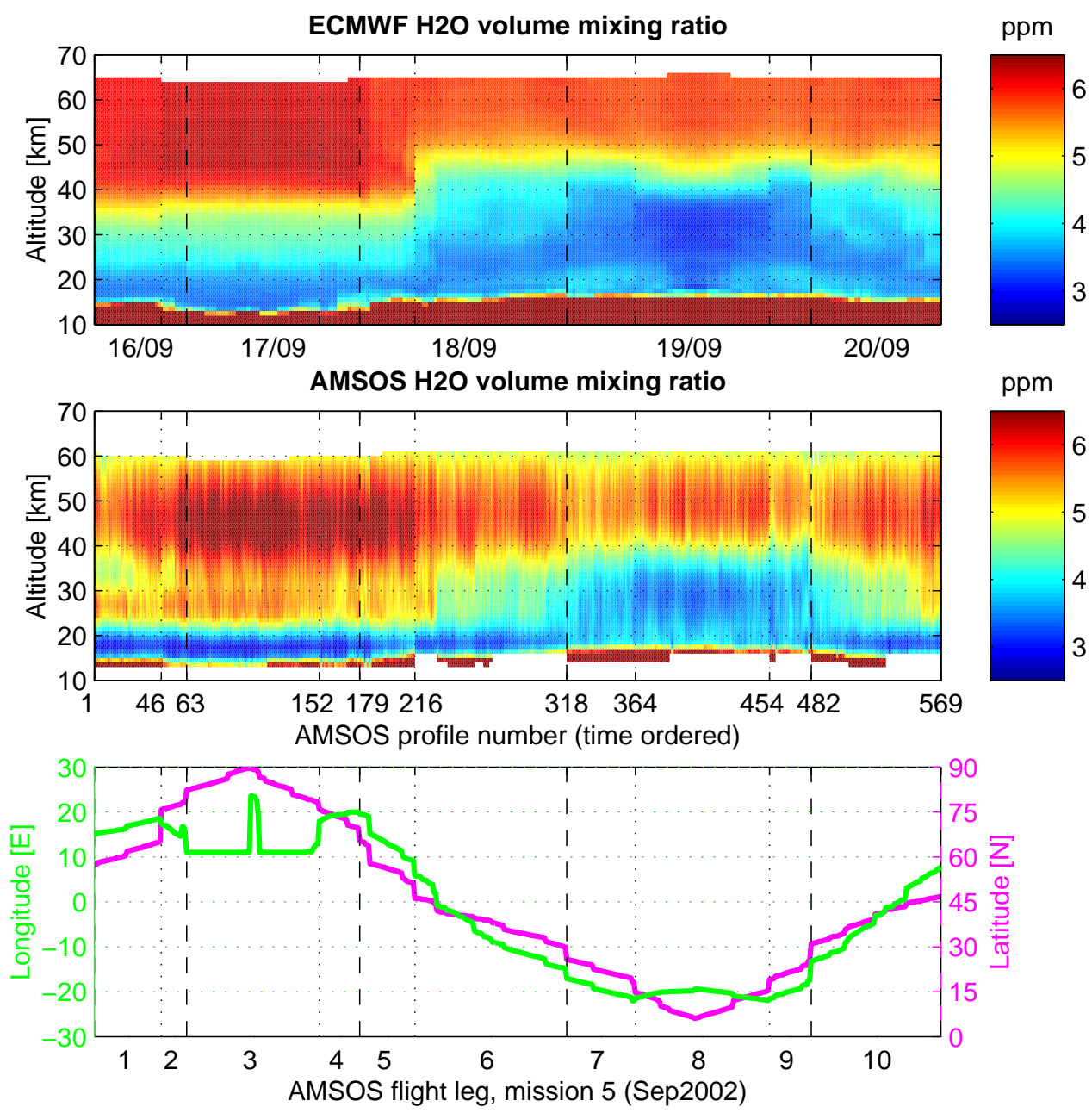

Fig. 6. Similar to Fig. 5 but for AMSOS Mission 5 (16-20 September 2002). The ECMWF humidity profiles are from the operational data set because ERA-40 ended in August 2002.

to the stratopause, and show lower humidities in the tropics and subtropics compared to the high latitudes. However, AMSOS shows rapdily decreasing humidities above the stratopause, but ECMWF shows only a minor decrease. Here, water vapour is removed through photolysis. These levels are very close to the ECMWF model top, and the photolysis term included in the water vapour chemistry parametrisation (Eq. 1) does not appear to be capable of reducing water vapour amounts to those observed by AMSOS. In general, the UARS climatology also shows a water vapour maximum somewhere between $1-0.1 \mathrm{hPa}$ with decreasing values above.

In the late winter/early spring situation of mission 3 (March 2000), mesospheric air has descended into the wintertime vortex (Fig. 5, profiles 64 to 186). AMSOS observations show low humidities characteristic of mesospheric air down to $\sim 45 \mathrm{~km}$. Air in the mesosphere in the ECMWF model has mixing ratios similar to those in the upper strato- sphere, so the analyses, unlike the observations, show similar mixing ratios inside and outside the vortex.

Figure 7 shows AMSOS retrievals for mission 3 (March 2000) on three isentropic levels, mapped to the corresponding ECMWF-derived equivalent latitude. Also shown are the UARS climatology and the ECMWF humidities at the corresponding AMSOS locations. There is a larger scatter in the AMSOS observations than in the other observations. It is likely that some of the scatter in AMSOS reflects true atmospheric variability on horizontal scales smaller than those represented in the analyses, but some variability may be due to instabilities in the measurement system. We do not expect the climatology to represent such scales at all.

At $430 \mathrm{~K}$ (approx. $90 \mathrm{hPa}$ ), all the datasets show higher humidities at high equivalent latitudes than at low equivalent latitudes, but the range of values is much smaller in the ECMWF analyses. 

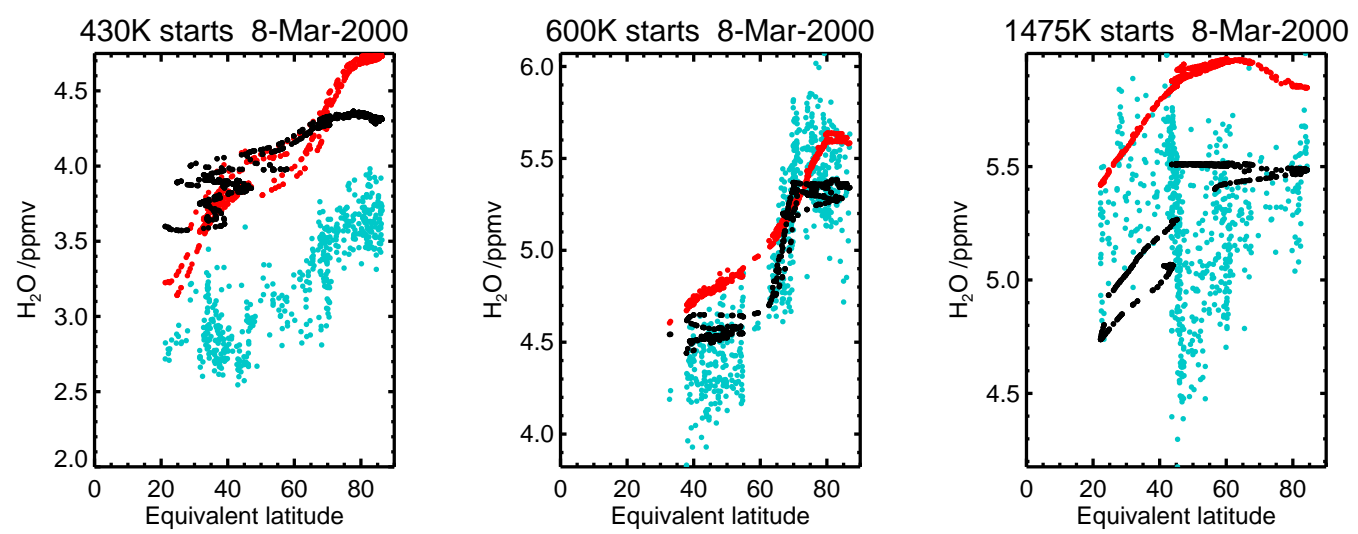

Fig. 7. AMSOS retrievals in March 2000 (blue), and at AMSOS locations the UARS climatology (red) and ECMWF analyses (black), against PV equivalent latitude on isentropic surfaces at (a) $430 \mathrm{~K}$, (b) $600 \mathrm{~K}$ and (c) $1475 \mathrm{~K}$.

(a)

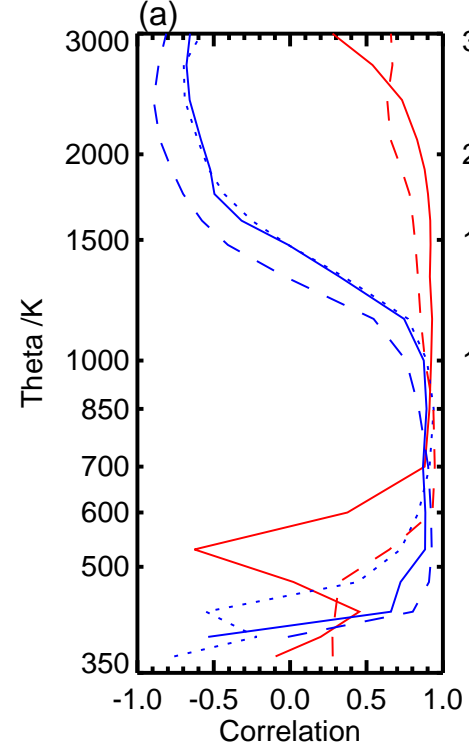

(b)

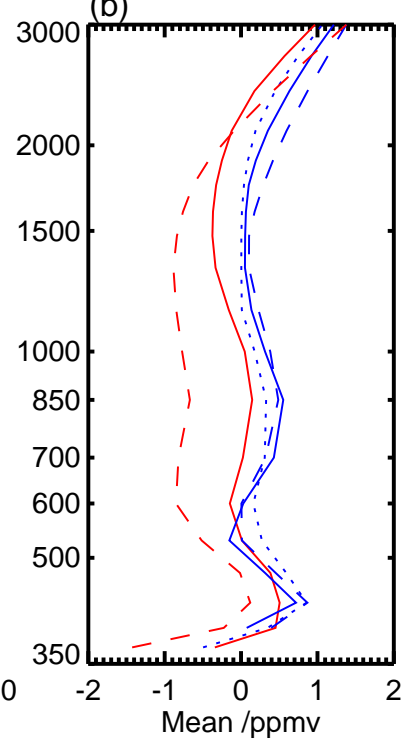

Fig. 8. (a) Pearson correlation coefficient between ECMWF and AMSOS humidities, and (b) Mean of ECMWF - AMSOS humidity, evaluated on isentropic levels and using all available retrievals from missions 1 (1998, solid red), 2 (1999, solid blue), 3 (2000, dashed blue), 4 (2001, dotted blue) and 5 (2002, dashed red). Red denotes a summer mission and blue a winter mission.

At $600 \mathrm{~K}$ (approx. $40 \mathrm{hPa}$ ), there is a clear vortex edge in all three datasets at around $70^{\circ} \mathrm{N}$ in equivalent latitude. Both ECMWF and AMSOS show a sharp boundary and relatively constant mixing ratios either side of this. The UARS climatology shows a less distinct edge, and mixing ratios that vary continuously with equivalent latitude. This is likely explained by the nature of the UARS climatology, being an average of many years' behaviour, compared to the instantaneous nature of the other two datasets. At $600 \mathrm{~K}$ the agree-

ment between AMSOS and ECMWF is extremely good at all latitudes sampled; this holds throughout the mid-stratosphere ( $475 \mathrm{~K}$ to $1000 \mathrm{~K}$, figures not shown).

At $1475 \mathrm{~K}$ (approx. $2 \mathrm{hPa}$ ), AMSOS observes low moisture values, which in Sect. 5.1 we associate with mesospheric air that has descended into the stratosphere in the polar vortex. As already noted, this is not represented in ECMWF analyses. The AMSOS observations of dry mesospheric air are, surprisingly, associated with equivalent latitudes of $45^{\circ} \mathrm{N}$ to $60^{\circ} \mathrm{N}$, and not the high equivalent latitudes that would be expected of the centre of the vortex. We used ERA$40 \mathrm{PV}$ distributions to map AMSOS observations onto equivalent latitudes. As we explain in Sect. 5.1, the unusual equivalent latitudes assigned to these observations are due to a feature in the ERA-40 PV distributions in the upper stratosphere winter vortex. In that section we also discuss the fact that the UARS climatology shows little sign of dry air at these levels.

To summarise similar comparisons covering all 5 missions and all levels, (Figs. 8 and 9) show the correlation and mean difference between ECMWF and AMSOS and between ECMWF and UARS climatology respectively. For each chosen level and each mission, statistics are calculated from the set of AMSOS, ECMWF and UARS data at AMSOS locations. The size of the sample varies with the mission, but lies between roughly 500 and 760 observations. We chose to summarise the agreement between datasets in terms of the linear (Pearson) correlation coefficient. This statistic is insensitive both to mean differences between datasets, and differences in standard deviations between datasets, a useful property given the obvious discrepancies at some levels in Fig. 7. A value of +1 indicates an exact linear dependence between two datasets.

Figure 8a shows that AMSOS and ECMWF are reasonably well correlated between $1200 \mathrm{~K}$ and $530 \mathrm{~K}$ in all missions except the first, which shows particularly poor correlations in the lower stratosphere. Above $1200 \mathrm{~K}$, there is 
good agreement for the summer missions but poor agreement for the winter missions, as there is no indication of descending dry mesospheric air in the ECMWF analyses. This poor agreement actually manifests itself as an inverse correlation at these levels: due to the Brewer-Dobson circulation, air at the poles in the ECMWF model will be older than that at the equator, and without a significant drying through photolysis in the model, the methane oxidation scheme makes this older, polar air moister. Hence the zonal pattern is completely opposite to that in the AMSOS observations.

At $475 \mathrm{~K}$ and below, correlations between AMSOS and ECMWF are in general worse (Fig. 8a). This reflects two main problems. First, there are deficiencies in the ERA40 lower stratospheric moisture. For example Oikonomou and O'Neill (2006) showed that there is excessive transport of moisture through the tropopause in summer; this is particularly obvious in mission 1 (not shown, see supplementary material at http://www.atmos-chem-phys.net/7/ 5291/2007/acp-7-5291-2007-supplement.pdf), where ERA40 has excessively high mixing ratios in the tropical lower stratosphere. Second, the quality of the AMSOS retrievals declines near the tropopause as can be seen in Fig. 2. Comparing to the ECMWF profiles, Fig. 5 suggests there is little useful information from AMSOS below $\sim 18 \mathrm{~km}$.

Figure $8 \mathrm{~b}$ shows that ERA-40 humidities are generally within $\pm 0.5 \mathrm{ppmv}$ of the AMSOS humidities between $500 \mathrm{~K}$ and $2000 \mathrm{~K}$. However, the operational analyses in 2002 are $\sim 0.8$ ppmv lower than AMSOS in the mid stratosphere $(600 \mathrm{~K}$ to $1500 \mathrm{~K})$. This is indicative of the substantially drier lower and mid stratosphere in the 2002 operational analyses, compared to ERA-40, which we identified in Sect. 3.3. Also, AMSOS retrievals appear to show a vertical oscillation that is quite consistent through all five missions, with humidities too low by $\sim 1$ ppmv at $425 \mathrm{~K}$ and up to $0.5 \mathrm{ppmv}$ too low at $850 \mathrm{~K}$. This is even evident in Fig. 5. Later, we see that this vertical oscillation is a problem with the AMSOS data.

Comparing ECMWF analyses to UARS climatology (Fig. 9a) reveals features broadly similar to the comparisons with AMSOS. The best correlations are in the mid and upper stratosphere (530 to $1500 \mathrm{~K}$ ). Winter correlations are negative above $\sim 2000 \mathrm{~K}$, where the UARS climatology also shows some sign of lower humidities due to mesospheric descent, and the ECMWF analyses do not. Correlations are relatively poor below $530 \mathrm{~K}$, particularly for the summer missions. Hence, the poor agreement between AMSOS and ECMWF in the summer missions in the lower stratosphere ( $400 \mathrm{~K}$ to $600 \mathrm{~K}$ ), particularly in August 1998, likely comes not just from limitations in the AMSOS retrievals at these levels, but also from problems with the ECMWF humidities.

Where correlations between ECMWF analyses and UARS climatology are large and positive, they are typically a little larger than the correlations obtained between ECMWF and AMSOS. This is likely because both the ECMWF and UARS climatology vary smoothly with equivalent latitude (Fig. 7), in contrast to the noisy distribution of AMSOS humidities.
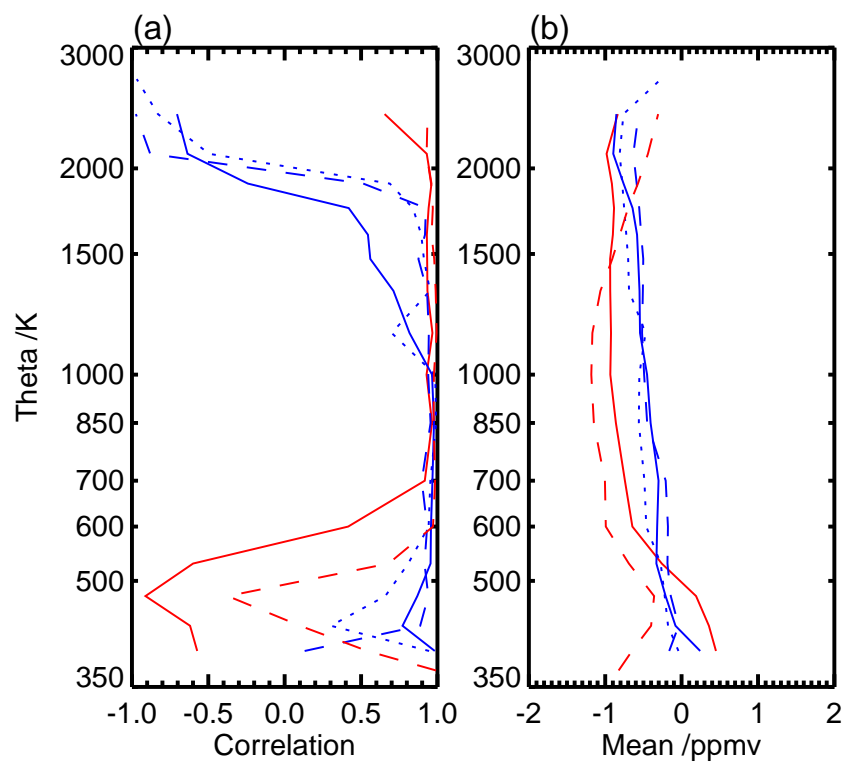

Fig. 9. (a) Pearson correlation coefficient between ECMWF humidities and UARS climatology humidities, and (b) Mean of ECMWF - UARS climatology. Other details as for Fig. 8.

ECMWF humidities are of order $0.5 \mathrm{ppmv}$ lower than UARS climatology (Fig. 9b), with the largest differences at the time of the 2002 missions, again reflecting differences between the 2002 operational analyses and the ERA- 40 data examined in other years. However, 2002 does not stand out as much as in the AMSOS comparisons (Fig. 8b). That there is no vertical oscillation in the comparisons between ECMWF and UARS suggests the oscillation found in the comparisons between ECMWF and AMSOS is a problem of the AMSOS data.

The following sections examine some of the differences between ECMWF and AMSOS in more detail. At a broad scale, above $600 \mathrm{~K}$ there is general agreement between AMSOS, ECMWF and UARS except that the ECMWF analyses do not represent the descent of dry mesospheric air in the winter polar vortex, and the UARS climatology shows only a limited representation of this. ERA-40 analyses also exhibit problems in the lowermost stratosphere (below $530 \mathrm{~K}$ ), and in particular there is excessive moisture in much of the lower stratosphere (430 K to $600 \mathrm{~K}$ ) in ERA-40 in August 1998.

\subsection{Mesospheric descent}

Here we further examine the descent of mesospheric air in the stratospheric wintertime polar vortex. Plumb et al. (2002) simulated the descent of mesospheric air (strongly diluted with surrounding stratospheric air) to $450 \mathrm{~K}$ (or $\sim 20 \mathrm{~km}$ ) by the end of the winter. Lahoz et al. (1994) found relatively dry air at $\sim 1000 \mathrm{~K}$ in MLS observations of the Northern Hemisphere winter vortex and linked this to descent from 
(a)

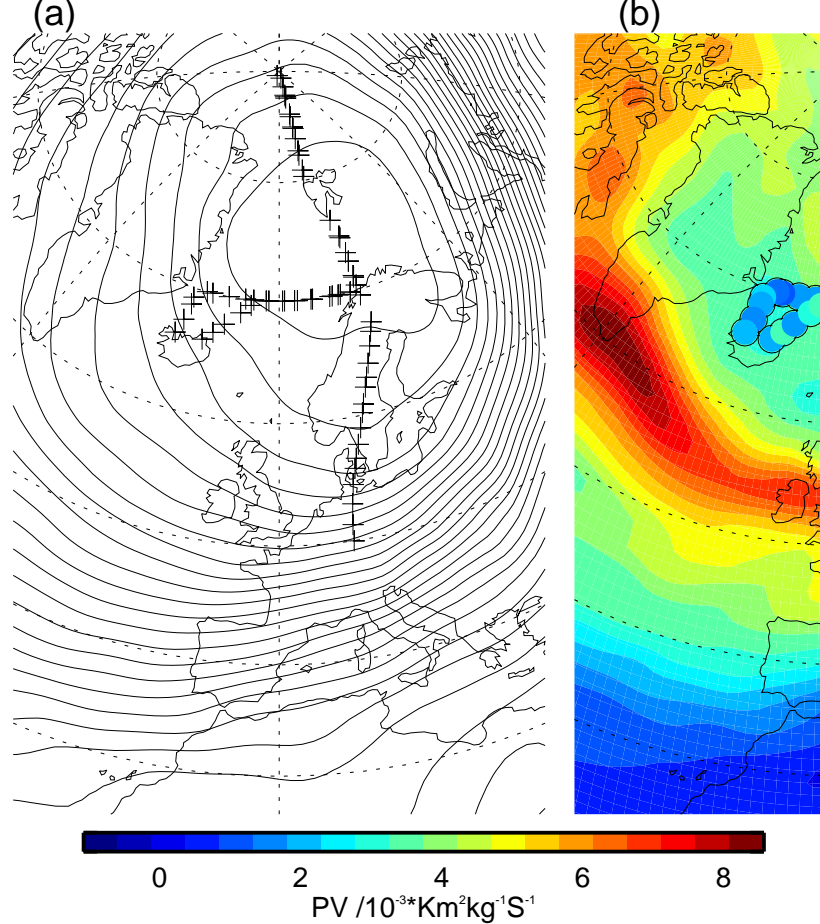

(c)

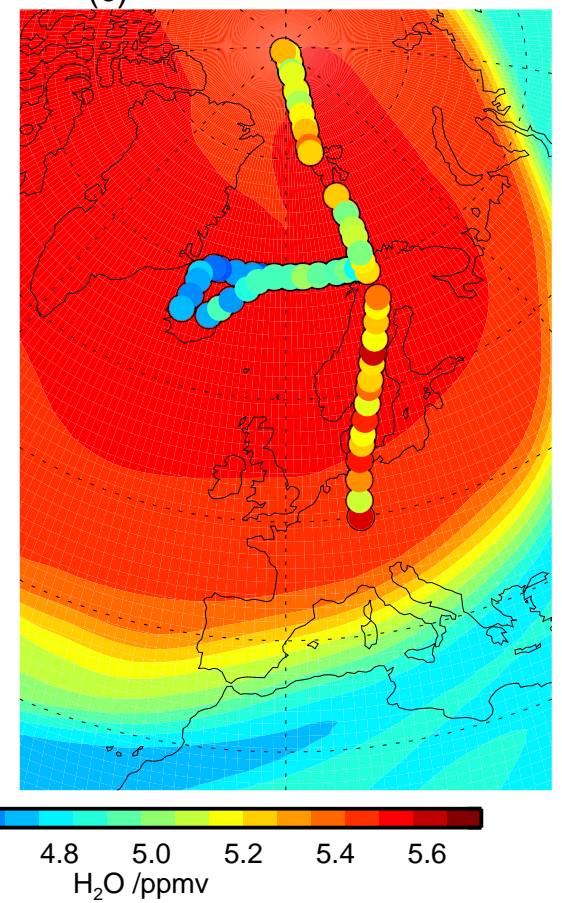

Fig. 10. ECMWF analyses for 12:00:00 UT on 9 March 2000: (a) Geopotential height on a 2 hPa surface with ten-minute averaged AMSOS observation points (crosses); (b) Potential vorticity on the $1475 \mathrm{~K}$ isentrope with AMSOS water vapour overlaid, represented by overlapping circles; (c) Water vapour mixing ratio on the $1475 \mathrm{~K}$ isentrope with AMSOS water vapour overlaid. AMSOS observations from 8 March 2000 to 10 March 2000 are shown.

the mesosphere. Aellig et al. (1996) observed descent of mesospheric air only to $1850-2000 \mathrm{~K}(\sim 50 \mathrm{~km})$ in March 1992. However, in winter/spring 2003, Engel et al. (2006) and Huret et al. (2006) observed a layer of air of mesospheric origin in the Northern Hemisphere vortex, descending from $30 \mathrm{~km}$ (January 2003) to $22 \mathrm{~km}$ (March 2003).

Figure 10 shows the meteorological situation in the upper stratosphere during the March 2000 mission, from ECMWF analyses. AMSOS moisture observations from 8 March 2000 to 10 March 2000 are superimposed. The geopotential height field at $2 \mathrm{hPa}$ (Fig. 10a) shows the polar vortex centred just $\mathrm{N}$ of Scandinavia; Fig. $10 \mathrm{~b}$ shows that $\mathrm{PV}$ is typically higher inside the vortex than outside. However, PV is lower in the centre of the vortex than it is elsewhere in the vortex. This is in contrast to the usual situation at lower levels (not shown), in which the vortex region defined by the geopotential height fields is entirely filled by relatively high PV. The origin of these low PV values in the upper vortex is not clear. If the low PV region had resulted from the transport of mid-latitude air to the vortex centre, there would likely be a similar low patch in the ECMWF water vapour mixing ratios. Instead, perhaps one hypothesis is the known problem of an oscillatory temperature structure in the polar winter/spring stratosphere in ERA-40 (Randel et al., 2004a; Uppala et al., 2005). To investigate further would be outside the scope of this paper. If we accept that the polar vortex is defined by the geopotential height field, the strange PV values do not really affect our analysis, except that they explain the surprisingly low equivalent latitudes of $45^{\circ} \mathrm{N}$ to $60^{\circ} \mathrm{N}$ assigned to the lowest AMSOS mixing ratios at $1475 \mathrm{~K}$ in Fig. $7 \mathrm{c}$.

To improve the visualisation in Fig. 10, and to reduce variability, the AMSOS observations have been averaged in blocks of $10 \mathrm{~min}$ duration. They still show relatively high variability compared to the ECMWF moisture field. Such variability would be expected of the real atmosphere, which should show filamentary structures on scales not represented in the analyses (see, e.g. Sutton et al., 1994). However, the variability in the AMSOS observations could also come from instrumental noise. Without further study, we cannot distinguish between the two.

In the ECMWF moisture field, the vortex is clearly marked by high mixing ratios. In contrast the overlaid AMSOS observations show that mixing ratios are very low in some areas of the centre of the vortex, and this can be explained by the descent of mesospheric air. Figure 5 shows that, according to the AMSOS observations, air with low humidities and hence likely of mesospheric origin has descended as low as $45 \mathrm{~km}$. Low humidity air is also seen inside the vortex down to $45 \mathrm{~km}$ in the February 1999 AMSOS observations (mission 2, see e.g. Fig. 11). In November 2001 (mission 4) there are also 
(a)

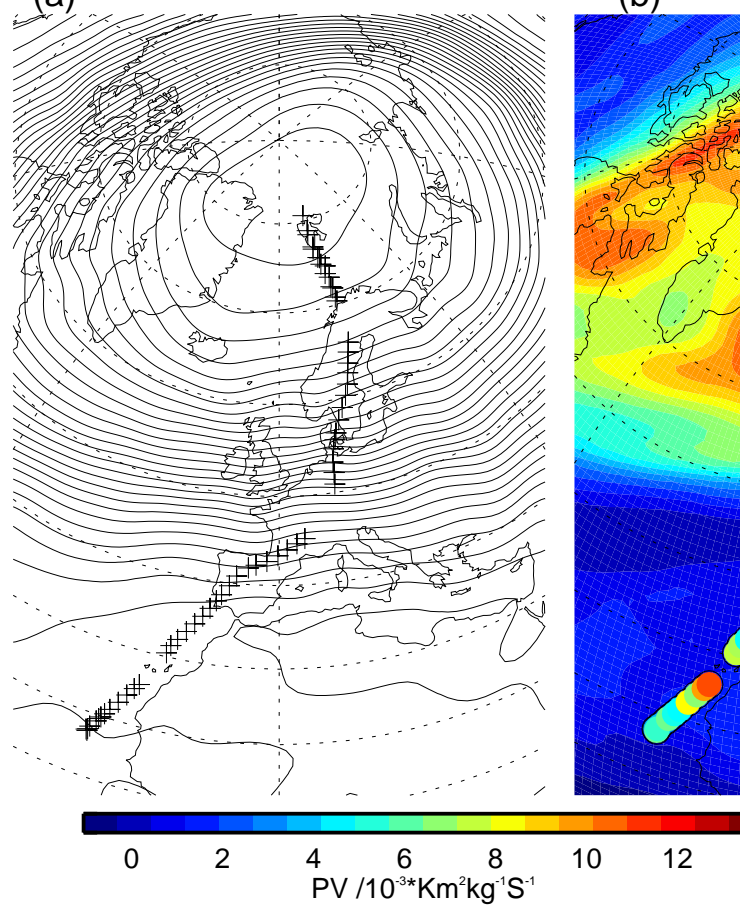

(c)

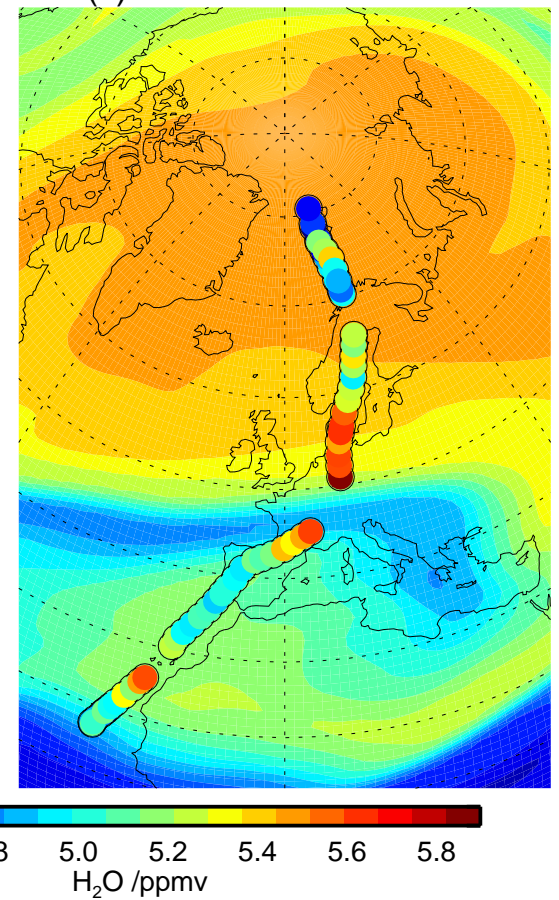

Fig. 11. ECMWF analyses for 12:00:00 UT on 6 February 1999: (a) Geopotential height on a $2 \mathrm{hPa}$ surface with ten-minute averaged AMSOS observation points (crosse); (b) Potential vorticity on the $1475 \mathrm{~K}$ isentrope with AMSOS water vapour overlaid, represented by overlapping circles; (c) Water vapour mixing ratio on the $1475 \mathrm{~K}$ isentrope with AMSOS water vapour overlaid.

indications of dry air descending in the vortex (not shown, see supplementary material at http://www.atmos-chem-phys. net/7/5291/2007/acp-7-5291-2007-supplement.pdf). Again, these features are not replicated in the ECMWF analyses. As already discussed, the ECMWF analyses cannot represent this because there is no effective source of dry mesospheric air in the model.

In contrast to the dry values seen in the AMSOS observations, the UARS climatology shows only a small decrease in moisture values in the winter upper stratosphere vortex (e.g. Fig. 7c). In January (Fig. 7 of Randel et al., 1998), mixing ratios are relatively low in the upper stratosphere winter vortex (north of $60 \mathrm{~N}$ equivalent latitude), but typical mixing ratios are $\sim 5.8 \mathrm{ppmv}$, much higher than the $\sim 5 \mathrm{ppmv}$ observed by AMSOS. Lahoz et al. (1994) examined some of the Northern Hemisphere winter MLS moisture observations on which the UARS climatology is based at polar latitudes. They observe relatively dry air in the mid-stratosphere $(\sim 1000 \mathrm{~K})$ and link this to descent from the mesosphere, but this relatively dry air still has mixing ratios of $\sim 6.2 \mathrm{ppmv}$. It is clear from the above-mentioned observational studies that mesospheric air descending in the stratospheric vortex may be patchy in spatial or temporal extent, and subject to interannual variability. Hence such features as we observe in AMSOS in March 2000 could easily be averaged out of the UARS climatology, or alternatively may not have been observed in the years for which MLS data was available.

To find out how representative the AMSOS observations are, it would be interesting to examine recent MLS observations from the Aura satellite (e.g. Manney et al., 2006); unfortunately the Envisat water vapour observations are of very poor quality in the winter vortex above $10 \mathrm{hPa}$ (Lahoz et al., 2006).

\subsection{Vortex boundaries}

During winter, below the level at which mesospheric air is important, diabatic descent in the vortex creates a situation of relatively high moisture inside the vortex, and low moisture outside. This is often explained in terms of the diabatic descent turning vertical gradients into "radial" (i.e. horizontal, equator to pole) gradients. Hence if the ECMWF analyses start with a reasonable approximation of the vertical gradient of moisture at the beginning of winter, as long as the diabatic descent is well-modelled in the system, the model should produce a reasonable estimate of the moisture distribution inside and outside the vortex, and should correctly simulate a vortex edge, represented by a sharp moisture gradient.

We see here that, in general, ECMWF moisture analyses do agree with AMSOS in terms of the positions of the vortex edge. Examples of this are Figs. 7a and b, with both datasets 
(a)

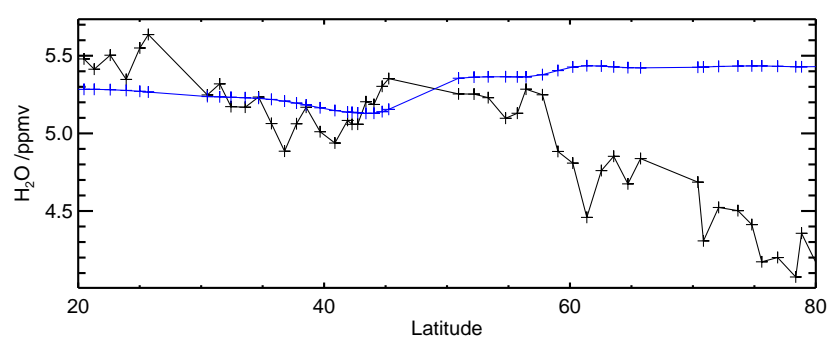

(b)

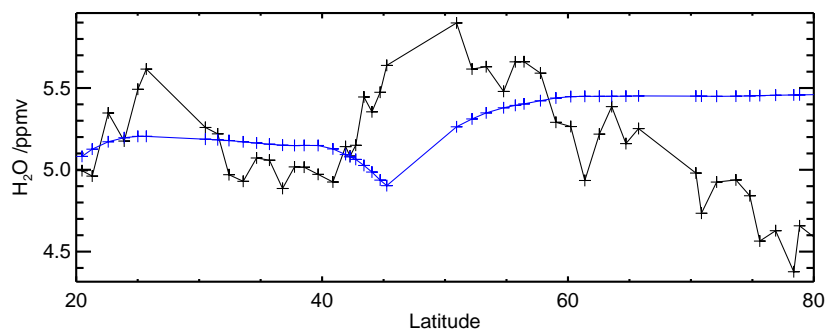

(c)

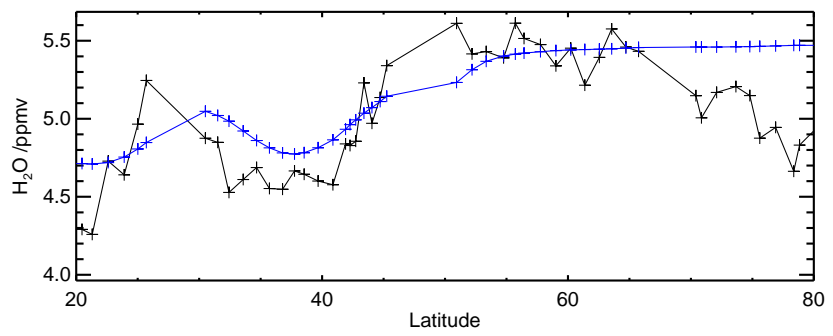

(d)

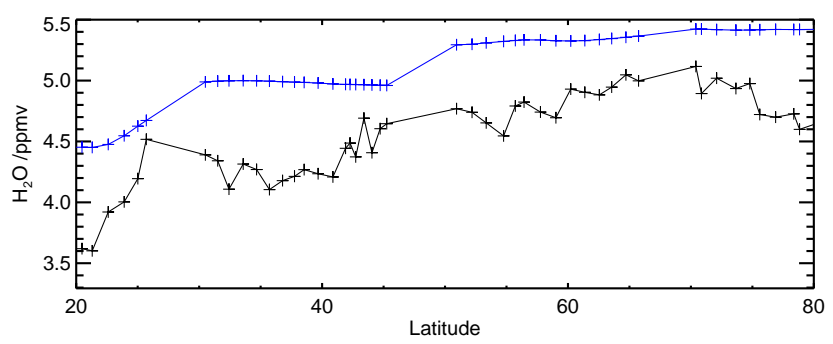

Fig. 12. ECMWF water vapour at AMSOS times and locations (blue) and ten-minute averaged AMSOS water vapour (black) on isentropes at (a) $1900 \mathrm{~K}$, (b) $1475 \mathrm{~K}$, (c) $1150 \mathrm{~K}$, (d) $850 \mathrm{~K}$. Figure shows all data in the northbound flights from 6 February 1999 to 9 February 1999 in mission 2. For more details of the flight, see the equivalent of Fig. 5 in the supplementary material at http://www.atmos-chem-phys.net/7/5291/ 2007/acp-7-5291-2007-supplement.pdf.

showing the vortex edge at very similar equivalent latitudes. More generally, this agreement in terms of vortex location is reflected in the good correlations between AMSOS and ECMWF in all the winter missions through much of the mid stratosphere (Fig. 8a, $475 \mathrm{~K}$ to $1000 \mathrm{~K}$ ). However, the limited temporal and spatial coverage of the AMSOS missions does not allow more quantitative statistics on the exact positional agreement. As a qualitative example, Fig. 13 shows a typical example of the agreement between AMSOS and ECMWF. Three AMSOS flight legs are shown, for convenience, on the same figure, but note that the ECMWF data are valid for 9 March 2000, the day on which only the westerly flight leg was performed. This leg passed through the vortex edge, whose location in AMSOS matches well to the sharp gradient in both ECMWF PV and moisture. The southerly leg was performed on 8 March 2000 and the northerly leg was performed on 10 March 2000; when overlaid on the corresponding day's analyses, the location of the vortex edge is as well captured as for the westerly leg. However, there is a stronger contrast in water vapour amounts inside and outside the vortex in the AMSOS data (3.5 ppmv versus $4.5 \mathrm{ppmv}$ ) than in the ECMWF data (4.2 ppmv versus $4.7 \mathrm{ppmv}$ ). Without much further analysis, we cannot say if this is due to poorly modelled descent or mixing, or if the stratospheric moisture distribution was incorrect even before the onset of wintertime descent. Nonetheless, the vortex edge appears consistently located in both the AMSOS and ECMWF humidities.

\subsection{Filamentation}

Filamentation is expected in at the vortex edge during autumn, winter, and spring, throughout the vertical extent of the stratosphere (Appenzeller and Holton, 1997). Filaments tend to have a tilt with altitude, so they often appear as laminar structures in vertical profiles such as from satellite or radiosonde. A number of studies have observed filamentation or lamination events (e.g. Sutton et al., 1994; Manney et al., 2000; Müller et al., 2003; Lahoz et al., 2006).

We examined the ECMWF PV and moisture fields, and the AMSOS observations, for signs of filamentation. Only four examples coincided with the flight tracks. In the upper stratosphere in February 1999 there were clear signs of filamentation in both ECMWF and AMSOS observations. In November 2001 and September 2002 the ECMWF fields showed indications of filaments, though they did not cross the flight track as clearly or perpendicularly as in February 1999, and the AMSOS observations did not show anything at all. In August 1998, AMSOS shows signs of filamentation, but there is no confirmation from the ECMWF fields. Hence we concentrate on the February 1999 example.

Figure 11 shows the meteorological and moisture fields from ECMWF at $2 \mathrm{hPa}$ (geopotential height) and $1475 \mathrm{~K}$ (PV and moisture) for 6 February 1999. The polar vortex is centred near the North Pole, and encloses a region of high PV and high moisture. As discussed in Sect. 5.1 the patches of lower PV in the centre of the vortex may be erroneous. Overlaid are the AMSOS moisture values at $1150 \mathrm{~K}$ along the flight tracks for 6 February 1999 to 9 February 1999. The 
(a)

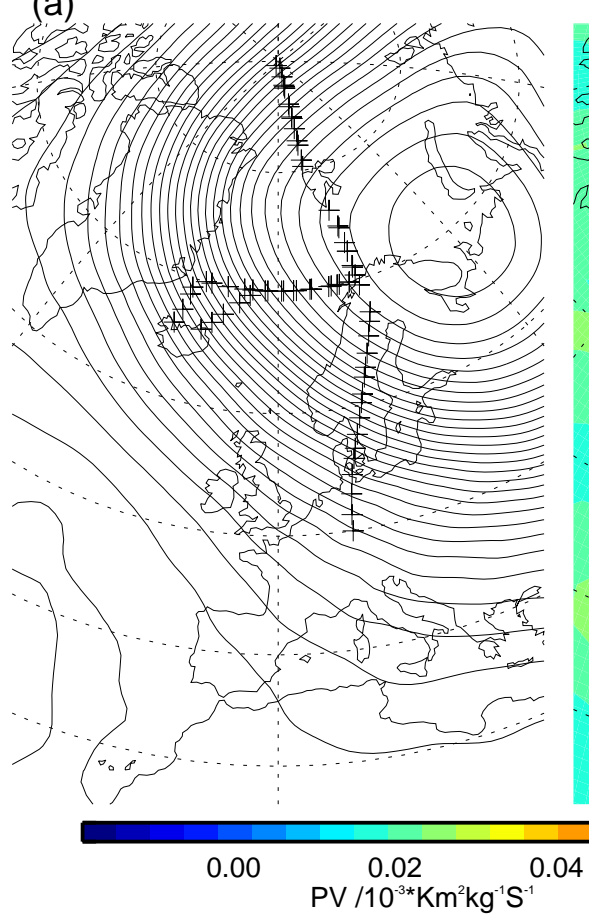

(b)

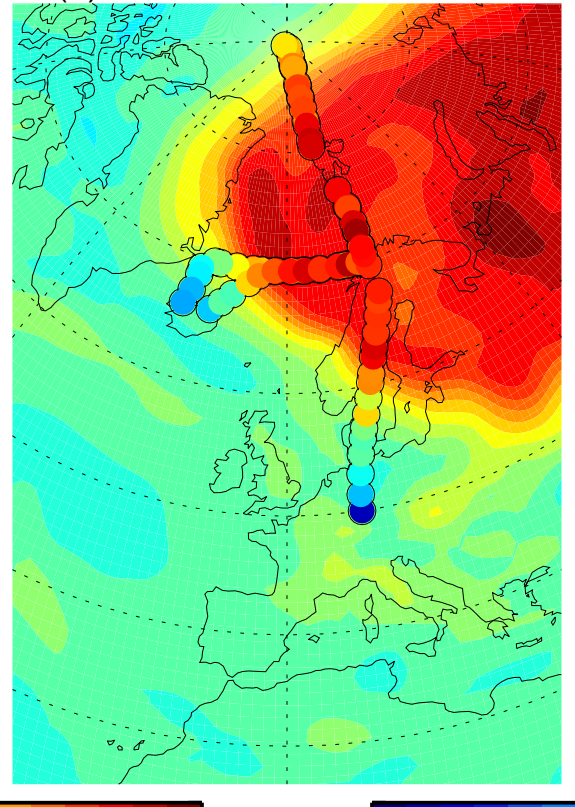

(c)

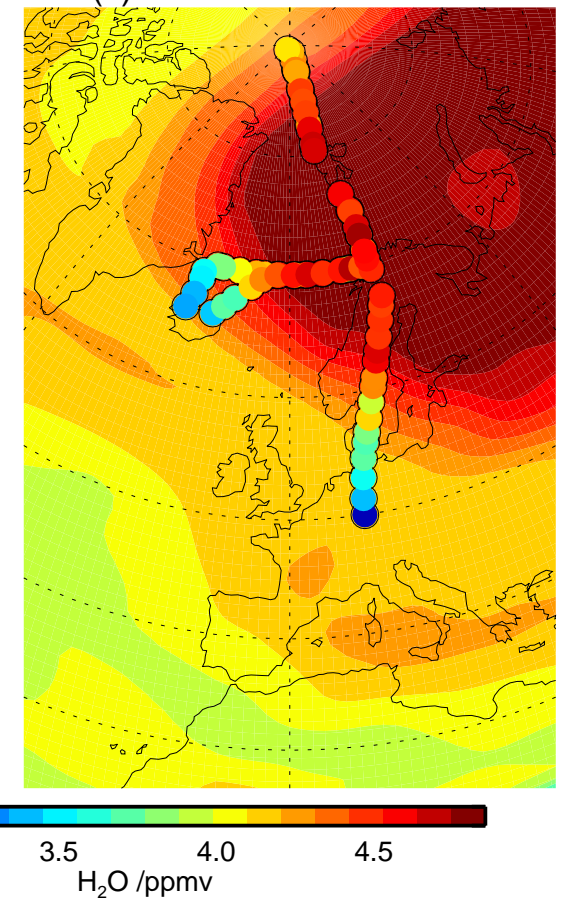

Fig. 13. ECMWF analyses for 12:00:00 UT 9 March 2000: (a) Geopotential height on a 50 hPa surface with ten-minute averaged AMSOS observation points (crosses); (b) Potential vorticity on the $475 \mathrm{~K}$ isentrope with AMSOS water vapour overlaid, represented by overlapping circles; (c) Water vapour mixing ratio on the $475 \mathrm{~K}$ isentrope with AMSOS water vapour overlaid. AMSOS observations from 8 March 2000 to 10 March 2000 are shown.

observations southwest of Spain were taken on 6 February 1999 itself. The AMSOS observations show clear signs of the descent of dry mesospheric air into the centre of the vortex.

There are filaments of dry and moist air in the ECMWF analyses in the lower half of Fig. 11c, associated with a small anticyclonic ridge. The analyses show dry midlatitude air being wrapped around the vortex and drawn eastwards over Europe, and a filament of moist vortex air being drawn westward over North Africa. There is a similar pattern in the PV field, though the PV values in the vortex filament have only a small contrast with that of the midlatitude air, which means this is hard to see with the smoothly varying colour scale used in Fig. 11b. The AMSOS observations show moist air in approximately the same position as in the ECMWF analyses, over the Canary Islands, but in AMSOS its width is much narrower. A region of dry air with mixing ratios typical of the midlatitudes is found to the southwest of Spain in the AMSOS observations, about $15^{\circ}$ to the south of its position in the ECMWF analyses.

Figure 12 examines the situation on selected isentropic levels. AMSOS observations are shown as averages of blocks of ten-minute duration, as in Fig. 11. The pattern of dry midlatitude air at roughly $35^{\circ} \mathrm{N}$ and moist vortex air at around $27^{\circ} \mathrm{N}$ is visible in the AMSOS fields at levels from $850 \mathrm{~K}$ $(\sim 35 \mathrm{~km})$ to $2400 \mathrm{~K}(\sim 55 \mathrm{~km}$, not shown). A similar pattern appears in the ECMWF moisture fields from $1150 \mathrm{~K}$ to $1900 \mathrm{~K}$, though its position varies with height, and is not in exactly the same place as in the AMSOS observations. We cannot say which dataset is correct in its description of the vertical behaviour of the filament. Filaments can tilt with altitude, though they do not always do so (e.g. Lahoz et al., 2006). The broad vertical resolution of AMSOS means that it may not be able to see such a tilt. Above $1900 \mathrm{~K}$, there is no gradient between the vortex and the midlatitudes in the ECMWF moisture fields, and so no filament could appear in the moisture analyses anyway. Therefore the lack of a filament in the ECMWF analyses between 1900 and $2400 \mathrm{~K}$ does not mean it should not exist in the AMSOS observations.

In summary, it appears that the ERA-40 analyses and AMSOS broadly agree in their representation of a filamentation event in water vapour fields in February 1999. Though the amplitudes and positions are not in exact agreement, its stratospheric vertical extent is similar in both datasets. Three other possible filamentation events in ECMWF or AMSOS were identified, but not shown, as there was no agreement between the two datasets. However, in two of those cases the AMSOS flight track was not very well positioned in time and space to capture the potential filament. Comparisons 


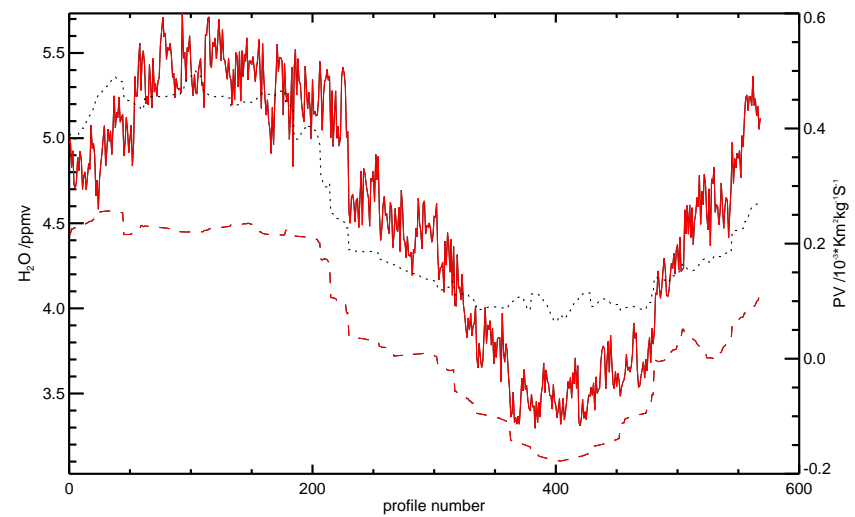

Fig. 14. ECMWF water vapour (red, dashed), PV (black, dotted) and AMSOS water vapour (red, solid) on the $850 \mathrm{~K}$ isentrope at mission 5 locations.

with more recent ECMWF operational analyses (Lahoz et al., 2006) have shown that the ECMWF PV distributions were able to match extremely well with satellite tracer observations of a planetary-scale filament extending around $180^{\circ}$ of longitude. The filaments investigated here are smaller in scale (only $90^{\circ}$ of longitude), and the ERA-40 assimilation system is in comparison less advanced in both algorithm (3D-Var instead of 4D-Var) and resolution (T159 vs. T511). Most other studies which have compared modelled and observed filaments have done so using Lagrangian trajectory techniques (e.g. Sutton et al., 1994; Manney et al., 2000), or PV-like advected tracers (Müller et al., 2003). The representation of the February 1999 filament directly in the ERA-40 moisture field and analysed PV is encouraging, especially considering that more recent operational analyses are likely of much better quality, as seen by Lahoz et al. (2006).

\subsection{2 operational analyses}

Section 3.3 showed that there were substantial differences in stratospheric moisture between ERA-40 and the 2002 operational ECMWF analyses. The upper stratosphere is moister in the operational analyses due to the change in the methane oxidation scheme. In the mid and lower stratosphere, operational analyses are drier, particularly in the moist phase of the tape-recorder. Note however that in late 2002, the moisture values in the upper stratosphere are still spinning up to a new level (see Figs. 3 and 6). We examine the 2002 operational analyses in more detail in this section.

In the tropics in both datasets, there is a minimum in moisture at about $30 \mathrm{~km}$. Values are higher at around $20 \mathrm{~km}$. This is consistent with the tape-recorder effect: higher moisture values come into the lowermost stratosphere around August. Above is a layer of drier air which would have come into the lowermost stratosphere around February, and has since ascended. However, this layer is much broader in the ver-

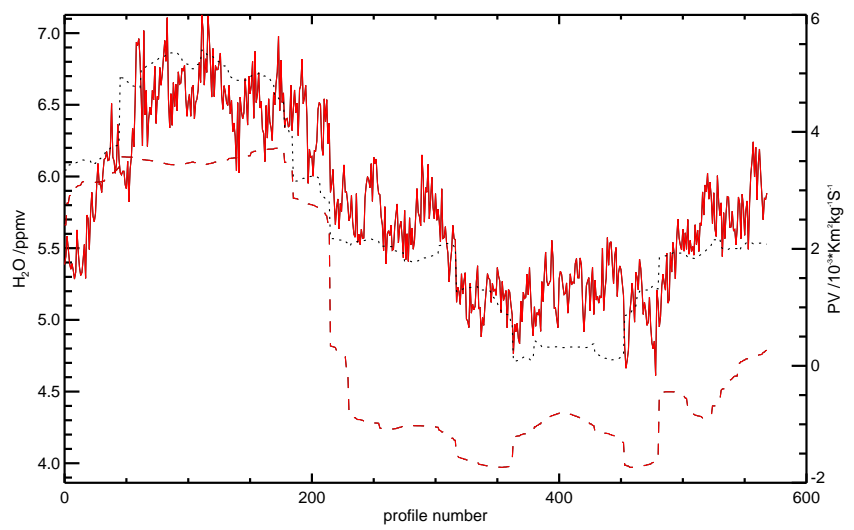

Fig. 15. ECMWF water vapour (red, dashed), PV (black, dotted) and AMSOS water vapour (red, solid) on the $1475 \mathrm{~K}$ isentrope at mission 5 locations.

tical in the ECMWF analyses than in the AMSOS observations, which at $40 \mathrm{~km}$ show a sharp transition in the vertical to higher moisture values. In the ECMWF analyses, the dry region extends higher in the atmosphere.

Figures 14 and 15 show isentropic cuts through the ECMWF and AMSOS data (shown at full time resolution) at $850 \mathrm{~K}$ and $1475 \mathrm{~K}$, respectively. ECMWF mixing ratios are generally lower than AMSOS at both levels. In tropical regions at $1475 \mathrm{~K}$, and in polar regions at $850 \mathrm{~K}$, the ECMWF data are as much as $\sim 1$ ppmv lower. The ECMWF PV analyses are also shown on the figure, and have variations with latitude similar to the moisture analyses.

At $850 \mathrm{~K}$, the AMSOS observations show a higher contrast $(\sim 2 \mathrm{ppmv})$ in moisture values between the north pole and the tropics compared to the ECMWF analyses ( $\sim 1.5 \mathrm{ppmv})$. Here, the UARS observations (not shown) agree more with the ECMWF analyses.

At $1475 \mathrm{~K}$, the moisture difference between the north pole and the tropics in the ECMWF analyses is $\sim 2$ ppmv, larger than that in the AMSOS data, which is $\sim 1.5 \mathrm{ppmv}$. The ECMWF operational analyses appear to be too dry in the tropical upper stratosphere, and comparisons with the UARS climatology (figures not shown) confirm this. Looking at figures similar to Fig. 15 for other levels (not shown), the ECMWF operational analyses in September 2002 are 0.5 to 1 ppmv drier than AMSOS between $1150 \mathrm{~K}$ and $1900 \mathrm{~K}$ (approximately $35 \mathrm{~km}$ to $50 \mathrm{~km}$ ) in the tropics.

A possible explanation for excessive dryness in the tropical upper stratosphere could be the speed of the upwards propagation of the dry air that comes through the tropical tropopause. If the air is moved too quickly to the upper stratosphere, it will not have had time to undergo sufficient moistening through methane oxidation. This would make the tropical upper stratosphere too dry. However, an equally valid hypothesis would be that the parametrised rate 
of methane oxidation is too slow. However, it is more likely that dryness in the tropical upper stratosphere would be explained by too-fast vertical ascent. Operational ECMWF wind fields are known to produce too-young age-of-air in the stratosphere and only the very most recent analysis versions have been able to correct this problem (Monge-Sanz et al., 2007). In contrast to the dry air in the tropics, air in the polar upper stratosphere has been subject to the methane oxidation scheme for more than enough time to relax the humidities to the levels typically found in those regions. Hence in the upper stratosphere, this would explain why the polar regions appear sufficiently moist but the tropics appear too dry compared to AMSOS and (figures not shown here) UARS climatology.

\section{Conclusions}

The comparison between AMSOS microwave humidity profiles and ECMWF water vapour analyses has helped to understand the qualities and limitations of both datasets. The comparison is necessarily limited to individual case studies since the flight tracks are extremely heterogeneous in space and time, and the five missions sample a wide range of different seasonal behaviour. ECMWF meteorological and moisture fields have helped confirm the geophysical realism of the AMSOS measurements, in particular supporting observations of filamentation around the polar vortex in the February 1999 mission. Though three other candidate filamentation events were represented only in one of the two datasets, we would ascribe this mostly to the fact that the AMSOS flight tracks were not in a such a good position to bisect the filament. The AMSOS observations also reveal the descent of dry air from the mesosphere in the polar vortex in the Northern Hemisphere winter missions of February 1999, March 2000 and November 2001. Relatively dry mesospheric air was observed to descend as low as $45 \mathrm{~km}$ in March 2000 in the AMSOS data.

Several interesting aspects of the stratospheric water vapour distribution in the ECMWF model can be learned from this study. Two that were already known (Uppala et al., 2005; Oikonomou and O'Neill, 2006) are that in ERA-40 the tape recorder is too fast and that the lower stratosphere in summer appears excessively moist. This appears particularly in the comparisons with the measurements from August 1998.

There have also been important changes from ERA-40 to the operational analysis in 2002. The operational analyses have a moister upper stratosphere than ERA-40 which is probably more realistic. The mid and lower stratosphere are drier, particularly in the moist phase of the tape recorder. But the upper stratosphere shows too great a contrast between the tropics and the pole compared to AMSOS measurements because the tropical upper stratosphere appears too dry. Again, this may be due to too-fast vertical transport.
Compared to AMSOS observations, ERA-40 and 2002 operational analyses are too moist above $2000 \mathrm{~K} / 55 \mathrm{~km}$. Neither represents a realistically dry lower mesosphere, despite a parametrisation of the photolysis of water vapour. Good behaviour here is hardly to be expected, as the lower mesosphere is represented only by a few levels close to the model top. However, as a result, the mesospheric air descending into the winter polar vortex is too moist. AMSOS shows relatively dry air down to $45 \mathrm{~km}$; neither ERA-40 nor ECMWF operational analyses can represent this. Humidity from ECMWF is therefore potentially unreliable throughout the winter polar stratosphere, since such dry air has been observed as low as $22 \mathrm{~km}$ (Huret et al., 2006). It would certainly be worthwhile to re-examine ECMWF's future operational analyses against future data, as the new operational system now reaches further into the mesosphere. After the introduction of cycle31r1 in the fall of 2006 (A. Simmons, personal communication) this should allow at least in principle for polar wintertime descent of dry air into the stratosphere.

There are discrepancies between PV and water vapour in the centre of the upper stratospheric vortex in ERA-40: the centre of the vortex shows patches of unexpectedly low PV. These remain unexplained. Despite this, vortex boundaries show reasonable approximate agreement with AMSOS observations and the filament example showed positional agreement to 15 degrees of latitude. This suggests that despite other limitations, filaments and vortex boundaries are at least represented approximately in the ERA-40 moisture analyses. More recent ECMWF analyses are likely substantially better at representing such events, as suggested by the good agreement between a filament in ECMWF PV and Envisat observations in Lahoz et al. (2006)

This study has also improved understanding of the AMSOS observations. Initial comparisons using AMSOS version 1 retrievals revealed a number of artifacts that could be traced back to problems in the observed spectra. In response we developed version 2 of the retrievals, with better screening of spectra and an improved retrieval method. Version 2 is used throughout this paper and shows substantially better data quality. This shows the advantage of comparing to analyses rather than just the few possible colocations that can usually be found with independent data. In this approach, every AMSOS profile could be included and put into meteorological context. One new artifact was discovered in the Version 2 data: there are coherent vertical oscillations that did not appear in version 1 . They are most likely due to the fact that fewer (and therefore noisier) spectra were used to retrieve the individual profiles and that a weaker regularization scheme based on ERA-40 climatology was used.

It should be noted that no effort was made to make AMSOS version 2 look more like ECMWF or satellite measurements like HALOE. The process of weeding out ununsable spectra through an improved quality control took place on the level of raw and calibrated individual spectra - not retrieved profiles. 
The results of this study also illustrate another feature of the AMSOS data set. Given the rather broad vertical resolution of roughly $10 \mathrm{~km}$ in the AMSOS averaging kernels it was quite surprising to see features of the tropical upper troposphere appear in the retrieved AMSOS water vapour profiles. There was only qualitative agreement in this region but it has helped to understand how the AMSOS retrieval reacts to upper tropospheric humidity. As mentioned before, the AMSOS retrieval is also sensitive to the total water vapour column between the aircraft and the hygropause. However, the agreement between the retrieved values and the data from ECMWF appears to be only qualitative. The possibility of useful upper tropospheric humidity retrievals has not been explored.

Later AMSOS missions like the SCOUT-O3 campaign to Darwin, Australia, in November 2005 have focused more on the tropics than on the arctic. The retrieved profiles will be analysed using the same techniques that have been established in this study and will probably benefit from the enhanced vertical and horizontal resolution of the ECMWF data. The upper-tropospheric humidity layer in the AMSOS retrievals which has not been exploited yet may be useful in this context. Another issue that may be investigated further with the help of AMSOS data is the role of mesospheric descent in the polar vortex which has recently drawn some attention in the published literature (e.g. Engel et al., 2006; Huret et al., 2006).

Acknowledgements. We would like to thank the Swiss Air Force and especially the pilots for their excellent support that they have given us during our campaigns.

Thanks are due to the British Atmospheric Data Centre for providing access to the Met Office Stratospheric Assimilated Data which was used for AMSOS version 1 and also for ECMWF data used by the University of Reading. We would also like to thank ECMWF for providing their analyses, to P. Berrisford and A. Stephens for helping prepare the ECMWF monthly mean humidities, and to A. Simmons from ECMWF for providing helpful comments and insight into the inner workings of the ECMWF stratospheric humidity model.

This work has been funded by COST action 723 and the Swiss National Science Foundation under grant 200020-107665. A. Geer was funded by the Assimilation of Envisat Data project (ASSET, http://darc.nerc.ac.uk/asset/), which is a shared-cost project (contract EVK2-CT-2002-00137) co-funded by the Research DG of the European Commission within the RTD activities of the Environment and Sustainable Development sub-programme (5th Framework Programme).

Edited by: P. Haynes

\section{References}

Aellig, C. P., Bacmeister, J., Bevilacqua, R. M., Daehler, M., Kriebel, D., Pauls, T., Siskind, D., Kämpfer, N., Langen, J., Hartmann, G., Berg, A., Park, J. H., and Russell III, J. M.: Space- borne $\mathrm{H}_{2} \mathrm{O}$ observations in the Arctic stratosphere and mesosphere in the spring of 1992, Geophys. Res. Lett., 23, 23252328, doi:10.1029/96GL01571, 1996.

Allen, D. R. and Nakamura, N.: Tracer Equivalent Latitude: A Diagnostic Tool for Isentropic Transport Studies, J. Atmos. Sci., 60, 287-304, doi:10.1175/1520-0469(2003)060<0287:TELADT $\rangle$. $0 . \mathrm{CO} ; 2,2003$.

Appenzeller, C. and Holton, J. R.: Tracer lamination in the stratosphere: A global climatology, J. Geophys. Res., 102, $13555-$ 13 570, doi:10.1029/97JD00066, 1997.

Bengtsson, L., Hagemann, S., and Hodges, K. I.: Can climate trends be calculated from reanalysis data?, J. Geophys. Res., 109, D11111, doi:10.1029/2004JD004536, 2004.

Brewer, A. W.: Evidence for a world circulation provided by the measurements of helium and water vapour distribution in the stratosphere, Q. J. Roy. Meteor. Soc., 75, 351-363, 1949.

Buehler, S. A., Eriksson, P., Kuhn, T., von Engeln, A., and Verdes, C.: ARTS, the atmospheric radiative transfer simulator, J. Quant. Spectrosc. Radiat. Transfer, 91, 65-93, doi:10.1016/j.jqsrt.2004. 05.051, 2005.

Dethof, A.: Aspects of Modelling and Assimilation for the Stratosphere at ECMWF, SPARC Newsletter 21, 2003.

Engel, A., Möbius, T., Haase, H.-P., Bönisch, H., Wetter, T., Schmidt, U., Levin, I., Reddmann, T., Oelhaf, H., Wetzel, G., Grunow, K., Huret, N., and Pirre, M.: Observation of mesospheric air inside the arctic stratospheric polar vortex in early 2003, Atmos. Chem. Phys., 6, 267-282, 2006, http://www.atmos-chem-phys.net/6/267/2006/.

Eriksson, P., Jimenez, C., and Buehler, S. A.: Qpack, a general tool for instrument simulation and retrieval work, J. Quant. Spectrosc. Radiat. Transfer, 91, 47-64, doi:10.1016/j.jqsrt.2004.05. 050, 2005.

Fleming, E. L., Chandra, S., Barnett, J. J., and Corney, M.: Zonal mean temperature, pressure, zonal wind and geopotential as functions of latitude, in: CIRA 1986, COSPAR International Reference Atmosphere Part I: Middle Atmosphere Models, edited by: Rees, D., Barnett, J. J., and Labitzke, K., Adv. Space Res., 10(2), (12)11-(12)59, doi:10.1016/0273-1177(90) 90386-E, 1990.

Fueglistaler, S., Bonazzola, M., Haynes, P. H., and Peter, T.: Stratospheric water vapor predicted from the Lagrangian temperature history of air entering the stratosphere in the tropics, J. Geophys. Res., 110, D08107, doi:10.1029/2004JD005516, 2005.

Huret, N., Pirre, M., Hauchecorne, A., Robert, C., and Catoire, V.: On the vertical structure of the stratosphere at midlatitudes during the first stage of the polar vortex formation and in the polar region in the presence of a large mesospheric descent, J. Geophys. Res., 111, D06111, doi:10.1029/2005JD006102, 2006.

Kley, D., Russell III, J. M., and Phillips, C. (Eds.): SPARC assessment of upper tropospheric and stratospheric water vapour, no. WCRP-113 in World Climate Research Programme Reports, SPARC Office, BP 3, 91371 Verrières le Buisson Cedex, France, 2000.

Lahoz, W. A., O’Neill, A., Carr, E. S., Harwood, R. S., Froidevaux, L., Read, W. G., Waters, J. W., Kumer, J. B., Mergenthaler, J. L., Roche, A. E., Peckham, G. E., and Swinbank, R.: Three-Dimensional Evolution of Water Vapor Distributions in the Northern Hemisphere Stratosphere as Observed by the MLS, J. Atmos. Sci., 51, 2914-2930, doi:10.1175/1520-0469(1994) 
051〈2914:TDEOWV〉2.0.CO;2, 1994.

Lahoz, W. A., Geer, A. J., and O'Neill, A.: Dynamical evolution of the 2003 southern hemisphere stratospheric winter using Envisat trace-gas observations, Q. J. Roy. Meteor. Soc., 132, 1985-2008, doi:10.1256/qi.05.221, 2006.

Le Texier, H., Solomon, S., and Garcia, R. R.: The role of molecular hydrogen and methane oxidation in the water vapour budget of the stratosphere, Q. J. Roy. Meteor. Soc., 114, 281-295, doi:10. 1256/smsqj.48001, 1988.

Manney, G. L., Michelsen, H. A., Irion, F. W., Toon, G. C., Gunson, M. R., and Roche, A. E.: Lamination and polar vortex development in fall from ATMOS long-lived trace gases observed during November 1994, J. Geophys. Res., 105, 29 023-29 038, doi:10.1029/2000JD900428, 2000.

Manney, G. L., Livesey, N. J., Jimenez, C. J., Pumphrey, H. C., Santee, M. L., MacKenzie, I. A., and Waters, J. W.: EOS Microwave Limb Sounder observations of "frozen-in" anticyclonic air in Arctic summer, Geophys. Res. Lett., 33, L06810, doi: 10.1029/2005GL025418, 2006.

Monge-Sanz, B. M., Chipperfield, M. P., Simmons, A. J., and Uppala, S. M.: Mean age of air and transport in a CTM: Comparison of different ECMWF analyses, Geophys. Res. Lett., 34, L04801, doi:10.1029/2006GL028515, 2007.

Morland, J., Deuber, B., Feist, D. G., Martin, L., Nyeki, S., Kämpfer, N., Mätzler, C., Jeannet, P., and Vuilleumier, L.: The STARTWAVE atmospheric water vapour database, Atmos. Chem. Phys., 6, 2039-2056, 2006, http://www.atmos-chem-phys.net/6/2039/2006/.

Mote, P. W., Rosenlof, K. H., Holton, J. R., Harwood, R. S., and Waters, J. W.: Seasonal variations of water vapor in the tropical lower stratosphere, Geophys. Res. Lett., 22, 1093-1096, doi:10. 1029/95GL01234, 1995.

Müller, M., Neuber, R., Fierli, F., Hauchecorne, A., Vömel, H., and Oltmans, S. J.: Stratospheric water vapour as tracer for vortex filamentation in the Arctic winter 2002/2003, Atmos. Chem. Phys., 3, 1991-1997, 2003, http://www.atmos-chem-phys.net/3/1991/2003/.

Oikonomou, E. K. and O'Neill, A.: Evaluation of ozone and water vapor fields from the ECMWF reanalysis ERA-40 during 1991-1999 in comparison with UARS satellite and MOZAIC aircraft observations, J. Geophys. Res., 111, D14109, doi:10.1029/ 2004JD005341, 2006.

Peter, R.: Stratospheric and mesospheric latitudinal water vapor distributions obtained by an airborne millimeter-wave spectrometer, J. Geophys. Res., 103, 16275-16290, doi:10.1029/98JD00968, 1998.

Plumb, R. A.: Stratospheric transport, J. Meteorol. Soc. Japan, 80, 793-809, 2002.

Plumb, R. A., Heres, W., Neu, J. L., Mahowald, N. M., del Corral, J., Toon, G. C., Ray, E., Moore, F., and Andrews, A. E.: Global tracer modeling during SOLVE: High-latitude descent and mixing, J. Geophys. Res., 108, 8309, doi:10.1029/2001JD001023, 2002.
Randel, W., Udelhofen, P., Fleming, E., Geller, M., Gelman, M., Hamilton, K., Karoly, D., Ortland, D., Pawson, S., Swinbank, R., Wu, F., Baldwin, M., Chanin, M.-L., Keckhut, P., Labitzke, K., Remsberg, E., Simmons, A., and Wu, D.: The SPARC Intercomparison of Middle-Atmosphere Climatologies, J. Climate, 17, 986-1002, doi:10.1175/1520-0442(2004)017〈0986:TSIOMC $\rangle 2$. $0 . \mathrm{CO} ; 2,2004 \mathrm{a}$.

Randel, W. J., Wu, F., Russell III, J. M., Roche, A., and Waters, J. W.: Seasonal cycles and QBO variations in stratospheric $\mathrm{CH}_{4}$ and $\mathrm{H}_{2} \mathrm{O}$ observed in UARS HALOE data, J. Atmos. Sci., 55, 163-185, doi:10.1175/1520-0469(1998)055〈0163:SCAQVI〉 2.0.CO;2, 1998 .

Randel, W. J., Wu, F., Oltmans, S. J., Rosenlof, K., and Nedoluha, G. E.: Interannual Changes of Stratospheric Water Vapor and Correlations with Tropical Tropopause Temperatures, J. Atmos. Sci., 61, 2133-2148, doi:10.1175/1520-0469(2004)061/2133: ICOSWV $>2.0 . \mathrm{CO} ; 2,2004 \mathrm{~b}$.

Rodgers, C. D.: Inverse Methods for Atmospheric Sounding: Theory and Practice, vol. 2 of Series on atmospheric, oceanic and planetary physics, World Scientific Publishing Co. Pte. Ltd., P.O. Box 128, Farrer Road, Singapore 912805, 2000.

Simmons, A. J., Untch, A., Jakob, C., Kallberg, P., and Unden, P.: Stratospheric water vapour and tropical tropopause temperatures in ECMWF analyses and multi-year simulations, Q. J. Roy. Meteor. Soc., 125, 353-386, doi:10.1256/smsqj.55316, 1999.

Simmons, A. J., Hortal, M., Kelly, G., McNally, A., Untch, A., and Uppala, S.: ECMWF Analyses and Forecasts of Stratospheric Winter Polar Vortex Breakup: September 2002 in the Southern Hemisphere and Related Events, J. Atmos. Sci., 62, 668-689, doi:10.1175/JAS-3322.1, 2005.

Sutton, R. T., Maclean, H., Swinbank, R., O’Neill, A., and Taylor, F. W.: High-Resolution Stratospheric Tracer Fields Estimated from Satellite Observations Using Lagrangian Trajectory Calculations, J. Atmos. Sci., 51, 2995-3005, doi:10.1175/ 1520-0469(1994)051〈2995:HRSTFE $\rangle$ 2.0.CO;2, 1994.

Uppala, S. M., Kållberg, P. W., Simmons, A. J., Andrae, U., da Costa Bechtold, V., Fiorino, M., Gibson, J. K., Haseler, J., Hernandez, A., Kelly, G. A., Li, X., Onogi, K., Saarinen, S., Sokka, N., Allan, R. P., Andersson, E., Arpe, K., Balmaseda, M. A., Beljaars, A. C. M., Van De Berg, L., Bidlot, J., Bormann, N., Caires, S., Chevallier, F., Dethof, A., Dragosavac, M., Fisher, M., Fuentes, M., Hagemann, S., Hólm, E., Hoskins, B. J., Isaksen, L., Janssen, P. A. E. M., Jenne, R., McNally, A. P., Mahfouf, J.-F., Morcrette, J.-J., Rayner, N. A., Saunders, R. W., Simon, P., Sterl, A., Trenberth, K. E., Untch, A., Vasiljevic, D., Viterbo, P., and Woollen, J.: The ERA-40 re-analysis, Q. J. R. Meteorol Soc., 131, 2961-3012, doi:10.1256/qj.04.176, 2005.

Vasić, V., Feist, D. G., Müller, S., and Kämpfer, N.: An airborne radiometer for stratospheric water vapor measurements at 183 GHz, IEEE Trans. Geosci. Remote Sens., 43, 1563-1570, doi: 10.1109/TGRS.2005.846860, 2005. 